\title{
Aglomerações Econômicas no Sul-Sudeste e no Nordeste Brasileiro: Estruturas, Escalas e Diferenciais
}

- RICARDO MACHADO RUIZ*

\author{
- EdSON PAULO DOMINGUes **
}

\begin{abstract}
RESUMO
Esse artigo compara as aglomerações econômicas espaciais dos Estados do Sul e Sudeste com as aglomerações espaciais do Nordeste. Dois temas foram focados: primeiro, a variedade e escala dos pólos econômicos nessas regiões e, segundo, as estruturas produtivas que sustentam essas aglomerações. $O$ estudo tem como referência uma base de dados com informações sobre 35.000 unidades produtivas (PIA 2000, PINTEC 2000 e SECEX 2000) e 5.507 municípios (ADH 2000, SIMBRASIL 2000, IPEA Data, IBGE 2000), além de informações sobre produção científica e tecnológica, serviços e agricultura. A partir desses dados as aglomerações econômicas foram identificadas e suas estruturas produtivas foram caracterizadas.
\end{abstract}

\section{PalavRAS-CHAVE}

aglomerações, desigualdade regional, localização, Brasil

\section{ABSTRACT}

This paper compares the spatial economic agglomerations of the South and Southeast Brazilian states with the one composed by the Northeast Brazilian states. Two issues were discussed: first, the number and scale of the economic cores in the regions; and second, the productive structures that sustain those agglomerations. The study is based on a set of data with 35,600 manufacturing firms (PIA 2000, PINTEC 2000 e SECEX 2000) and 5,507 municipalities in Brazil (ADH 2000, SIMBRASIL 2000, IPEA Data, IBGE 2000), and information on scientific and technological production, services and agriculture. Based on this information, the economic agglomerations were identified and their productive structures were characterized.

\section{KEYWORDS}

agglomerations, regional inequalities, location, Brazil

\author{
JEL CLASSIFICATION \\ $R / I, R / 2, R 23, R 30, R 58$
}

\footnotetext{
* Professor Adjunto e Pesquisador - Produtividade em Pesquisa - CNPq, FACE-UFMG e CEDEPLAR-UFMG. Endereço para contato: Faculdade de Ciências Econômicas - FACE -Centro de Desenvolvimento e Planejamento Regional CEDEPLAR - Universidade Federal de Minas Gerais - UFMG - Avenida Antônio Carlos, 6627 - CEP: 3 I 270-90I- Belo Horizonte - MG - Tel: (3I) 34097075 -Fax: (3I) 3409 7203. E-mail: rmruiz@cedeplar.ufmg.br.

* Professor Adjunto e Pesquisador - Produtividade em Pesquisa - CNPq - FACE-UFMG e CEDEPLAR-UFMG. E-mail: epdomin@cedeplar.ufmg.br.

(Recebido em março de 2007. Aceito para publicação em maio de 2008).
} 


\section{INTRODUÇÃO: A FORMAÇÃO DOS CENTROS E DAS PERIFERIAS}

Desde sua origem, a industrialização das economias capitalistas explora vantagens de escala da concentração espacial. O Brasil não foge a essa regra: o padrão locacional da indústria ao longo da industrialização foi centrípeto, concêntrico e hierárquico. Essas desiguais organizações da produção e da distribuição da renda no espaço têm atraído a atenção de pesquisadores há muito tempo. Os clássicos estudos de Furtado (1959) e de Prado (1959) são testemunhas dessa histórica preocupação com as diferenças regionais brasileiras.

A industrialização e a urbanização estiveram sempre articuladas. No início do século 20, a cidade de São Paulo já emergia como um centro polarizador da economia que desafiava a força político-econômica da então capital, Rio de Janeiro. Em 1872, São Paulo tinha $8 \%$ da população brasileira e era o quinto Estado brasileiro. Já em 1940, São Paulo ultrapassou Minas Gerais e se tornou o maior Estado do País com mais de $17 \%$ da população, e em 2000, São Paulo mantém essa posição com mais de $20 \%$ da população nacional. Esse crescimento paulista foi puxado por uma expansão industrial que arrastou consigo os serviços produtivos e pessoais, o sistema financeiro, a especulação imobiliária e todas as outras formas de geração e apropriação de riqueza. A industrialização consolidou a hegemonia paulista e um modelo industrial centro-radial mediado pela crescente importância das cidades: emergiu uma hierarquia urbano-industrial extremamente desigual (LEMOS et al., 2003).

A industrialização paulista, urbana, intensiva em capital, integrada e centrípeta desenvolvia a economia, mas não ajudava na integração territorial. A expansão da urbano-industrial reafirmava um território com grandes vazios demográficos e imensas polarizações de riqueza. Essa expansão urbano-industrial acentuava os vazios no Norte e Centro-Oeste e ameaçava esvaziar o Nordeste. As disparidades regionais se acentuavam.

A concentração econômica progrediu até o início da década de 1970, quando o pólo primaz, a região metropolitana de São Paulo, passou a perder força. Uma das direções da desconcentração da atividade industrial da região metropolitana de São Paulo foram as cidades médias, especialmente do Sul e do Sudeste, que se tornaram potenciais receptoras de empreendimentos industriais intensivos em capital. Os limites dessa desconcentração estavam desenhados por um polígono geográfico formado por Belo Horizonte - Uberlândia - Londrina/Maringá - Porto Alegre - Florianópolis - São José dos Campos - Belo Horizonte (DINIZ, 1993, 1994).

Dentro da região Sul-Sudeste, a industrialização criou uma rede de cidades relativamente integrada, enquanto nas outras regiões manteve as populações urbanas con- 
centradas e isoladas nas capitais estaduais, locais preferenciais de um tênue e frágil processo de industrialização. As capitais estaduais tornaram-se espaços singulares, pois nelas se encontravam condições adequadas para uma produção industrial em larga escala que demandava vasta oferta de energia, todo tipo de transporte e comunicação, além de uma variedade de serviços produtivos, financeiros e pessoais que davam suporte às massivas aglomerações produtivas e populacionais.

Esses restritos espaços estaduais onde existiam condições gerais de produção reforçaram a primazia política das capitais com a co-localização da produção industrial. A força política juntou-se à força econômica. Diante de tal concentração de poder, as capitais estaduais surgiram como pólos de crescimento e se tornaram grandes regiões metropolitanas cercadas por frágeis cidades médias e inúmeras e marginalizadas cidades pequenas. Criou-se, assim, uma estrutura urbana fragmentada, fragilizada e polarizada. Não é por acaso que ainda hoje dentre as 15 maiores aglomerações urbanas do Brasil, 12 são capitais estaduais e todas são pólos industriais nacionais (LEMOS et al., 2003).

\section{FIGURA I - PÓLOS ECONÔMICOS E ÁREAS DE INFLUÊNCIA (1996)}
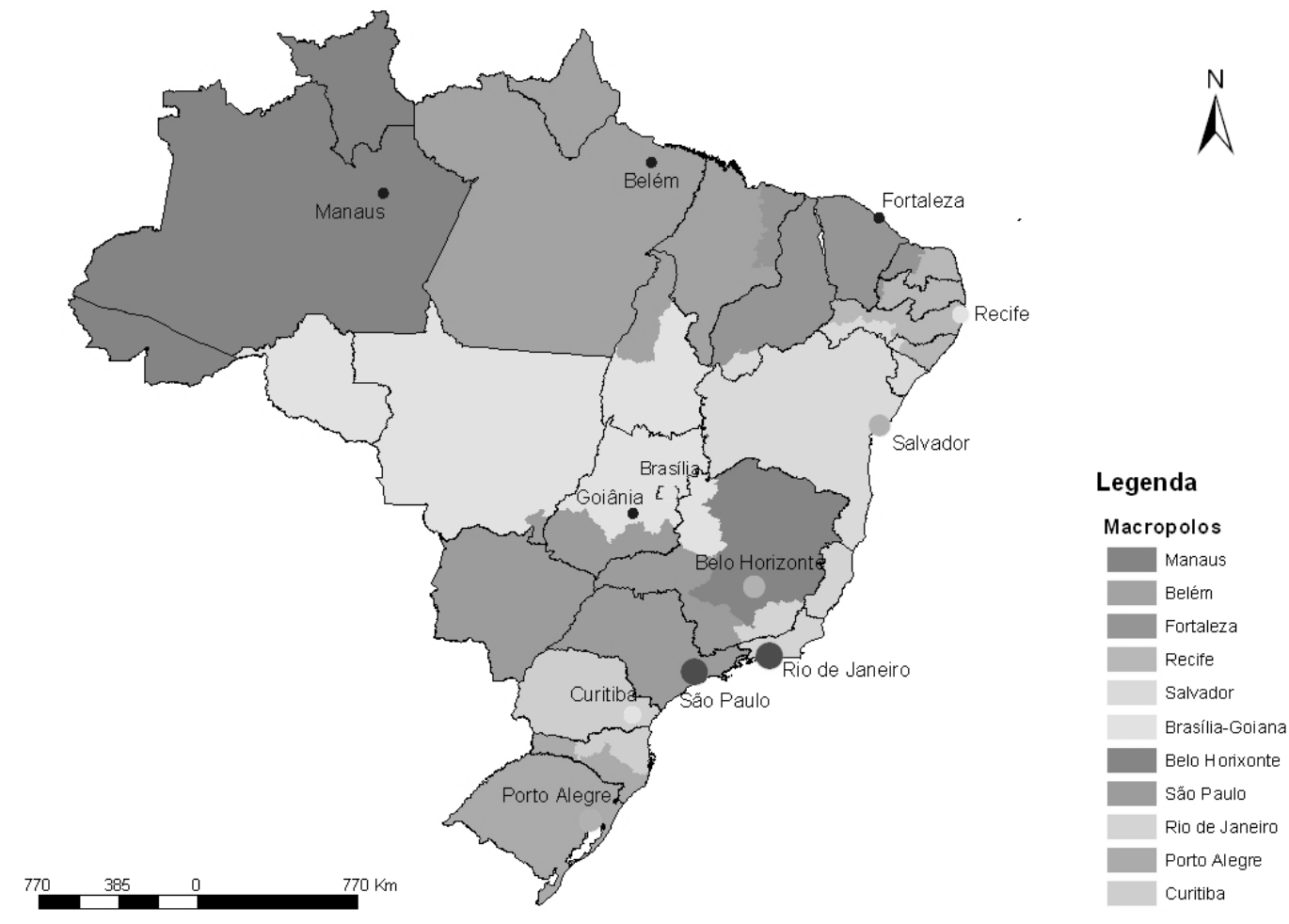

Fonte: Lemos et al. (2003). 
Fatores político-institucionais foram decisivos para atenuar a concentração da industrialização e podem ser considerados umas das principais forças centrípetas nesse processo. A integração do território nacional por meio de redes de transportes, de energia e de comunicação, as legislações nacionais que regulam os mercados de trabalho, os contratos privados, os impostos e as posses foram alguns mecanismos que favoreceram a difusão de condições produtivas em localidades antes marginalizadas. Outras políticas públicas estruturantes juntaram-se a essas, tais como a expansão das redes de esgoto, de abastecimento de água, a criação de escolas públicas e pontuadas políticas de habitação. Essas políticas difundiram as regras e estruturas da produção urbano-industrial.

Algumas intervenções no território podem contribuir para a concentração da atividade econômica, atuando como elemento de fortalecimento dos centros hegemônicos e enfraquecimento dos espaços periféricos. Este pode ser o caso dos investimentos em infra-estrutura de transportes e centros de desenvolvimento científico e tecnológico. Muitos destes investimentos tendem a se direcionar a estruturas já consolidadas de fluxos de produtos em processo de saturação, como nas rotas de exportação de produtos primários em direção a portos de escoamento (por exemplo, a soja do Mato Grosso em direção a Paranaguá, o minério de ferro de Minas Gerais para Vitória e a Ferrovia do Aço). Um exemplo recente são os investimentos previstos no Plano Nacional de Logística de Transportes (PNLT), que partem de uma estimativa dos gargalos e demandas futuras por transportes na rede atual e não têm como objetivo a criação de novas centralidades econômicas ou o atendimento de regiões desprovidas dessa infra-estrutura. Outro aspecto que se mostrou hoje uma importante força centrípeta foram os investimentos em ciência e tecnologia e formação de mão-de-obra qualificada, que são extremamente concentrados no espaço e são referências para qualquer investimento intensivo em tecnologia.

No sentido oposto, o amplo provimento de infra-estrutura básica e insumos difundidos possibilitaram não apenas a exploração dos recursos naturais do solo e subsolo nacional, como também o surgimento de novas centralidades urbanas subnacionais capazes de atrair atividades industriais e de estruturar redes urbanas regionais - por exemplo, os casos das rodovias federais Belém-Brasília, Cuiabá-Porto Velho, a BR116 e a polêmica rodovia Transamazônica. Esse sistema rodoviário foi decisivo para o surgimento de alguns pólos econômicos nacionais.

Nesse contexto, a política de subsídios e incentivos públicos cumpriu, algumas vezes, um papel complementar no estímulo à descentralização dos investimentos industriais. Assim, os bancos de desenvolvimento regional (BNB e BASA) e os fundos constitucionais (FCO, FNE e FNO) estiveram articulados aos investimentos industriais tanto do setor público como do privado, além dos conhecidos investimentos 
em infra-estrutura. Como exemplo, podem ser citados os casos da criação da Zona Franca de Manaus (AM), do Pólo Petroquímico de Camaçari (BA), do Vale do Aço (MG), além de investimentos públicos e privados em Carajás.

A construção de Brasília, a criação da Zona Franca de Manaus e as agências de desenvolvimento local (Sudene e Sudam) e empresas de desenvolvimento (e.g. Codevasf) foram, portanto, deliberadas tentativas de desenvolver regiões criando condições locais adequadas à industrialização e à urbanização. A recente ocupação do Centro-Oeste e a de regiões amazônicas são resultados diretos e indiretos, planejados e inesperados dessa miríade de políticas de desenvolvimento regional e local (MONTE-MÓR, 2004).

Ao mesmo tempo em que a urbanização avança nas fronteiras, nos centros urbanoindustriais a difusão das condições tecno-produtivas refinadas promove um transbordamento das atividades econômicas das capitais estaduais para alguns municípios do seu entorno: a sua periferia mais imediata. O exemplo mais notório dessa interiorização do desenvolvimento urbano-industrial é o Estado de São Paulo, onde cidades de pequeno e médio portes tornam-se receptoras de grandes indústrias e de uma complexa rede de serviços (AZZONI, 1986 e 1997; DINIZ, 1993 e 1994). O fenômeno da metropolização de algumas cidades - especialmente de algumas capitais estaduais - é parte desse processo de dispersão espacial seletiva, denominada "descentralização polarizada” (DINIZ; CROCCO, 1996; DINIZ, 1994).

\section{2}

\section{OBJETIVOS E METODOLOGLA}

A dinâmica espacial resultante da industrialização brasileira confirmou, por um lado, as teorias do desenvolvimento desigual, mas refletiu, por outro lado, a geopolítica da integração nacional. ${ }^{1}$ Dessa forma, a distribuição espacial da economia é concentrada pela força hegemônica de São Paulo e de seu entorno, mas existem pólos subnacionais que são forças efetivas de atração de investimentos. Pode-se dizer que o pólo nacional de São Paulo e os pólos subnacionais são os centros dinâmicos da economia no território nacional. Lemos et al. (2005a, 2005b e 2005c) confirmam e qualificam essas características do espaço polarizado brasileiro identificando e analisando as aglomerações industriais espaciais e os enclaves industriais no território nacional.

1 Empiricamente, o processo de desenvolvimento pode se caracterizar como oposto à convergência da renda e da atividade econômica, e assumir um caráter de desigualdade intrínseco entre regiões. Esta característica de desenvolvimento desigual já se encontrava nos trabalhos pioneiros da teoria de desenvolvimento, como Rosenstein-Rodan (1943), Nurske (1953), Hirschman (1958) e Myrdal (1957), e tem sido retomada em contribuições recentes (RAY, 1998; FUJITA et al., 1999). A geopolítica da integração nacional foi elemento decisivo no processo de criação de Brasília e em diversas iniciativas do governo federal na Amazônia a partir dos anos 1960 (BECKER, 2005). 
O objetivo deste trabalho é examinar detalhadamente a aglomeração da atividade econômica em dois conjuntos amplos de regiões contíguas: Sul-Sudeste e Nordeste. A hipótese subjacente na escolha destes dois agrupamentos é de que o primeiro é um espaço relativamente homogêneo na economia brasileira, no qual a expansão urbano-industrial estaria liberada de entraves gerados pela inexistência de condiçóes tecno-produtivas adequadas. Dentro desse espaço, os transbordamentos estariam presentes e explicitariam o jogo das forças centrípetas e centrífugas que organizam a produção capitalista no espaço. Também se acata que dentro dessa área existe uma lógica de organização da produção onde estruturas urbanas, tecnológicas e das firmas estariam imbricadas e moldariam as aglomerações econômicas a partir da estrutura produtiva e material. Por outro lado, a região Nordeste ainda carece de uma diversidade de condiçóes materiais para um transbordamento mais consistente dos seus centros para suas periferias.

Em suma, as duas regiões tratadas abarcam a área preferencial da produção capitalista no Brasil - o Sudeste - e uma área de industrialização restrita - o Nordeste (cf. DINIZ, 1993 e 1994). Nos tópicos seguintes, pretende-se avaliar as diferenças e escalas das aglomeraçóes econômicas nessas duas regiôes. Para isso, estatísticas de associação espacial e modelos econométricos são utilizados. A seguir, o banco de dados utilizado é apresentado.

\subsection{Base de dados}

Esse estudo comparativo das regióes Sul-Sudeste e Nordeste tem como referência uma base de dados com informaçôes sobre aproximadamente 35.000 unidades produtivas locais (PIA 2000, PINTEC 2000 e SECEX 2000) e 5.507 municípios (ADH 2000, SIMBRASIL 2000, IPEA Data, IBGE 2000), além de informações sobre serviços, produto agrícola, produção tecnológica e científica. Com esses dados, as aglomeraçóes econômicas foram identificadas e caracterizadas a partir da sua estrutura produtiva e material. ${ }^{2}$

2 Para maiores detalhes sobre a construção desse banco de dados, ver De Negri e Salermo (2005) e Lemos et al. (2005a). 
TABELA I - CARACTERÍSTICAS DAS FIRMAS INDUSTRIAIS BRASILEIRAS NA AMOSTRA (2000)

\begin{tabular}{lcccc}
\hline & \multicolumn{4}{c}{ Tipos de Firmas Industriais } \\
\hline Características & Inovadoras & Padronizadas & Competitivas & Todas \\
\hline Número de Firmas & 1.199 & 15.311 & 55.495 & 72.005 \\
Firmas como \% da amostra & 1,7 & 21,3 & 77,1 & 100,0 \\
Firmas de Capital Nacional (\%) & 1,1 & 20,2 & 78,7 & 100,0 \\
Firmas de Capital Estrangeiro (\%) & 24,6 & 68,1 & 1,6 & 100,0 \\
\hline Faturamento (\% do total) & 25,9 & 62,6 & 11,5 & 100,0 \\
Emprego (\% do total) & 13,2 & 48,7 & 38,2 & 100,0 \\
Pessoal Ocupado (mil pessoas) & 545,9 & 158,1 & 34,2 & - \\
Faturamento (R\$ milhões por firma) & 135,5 & 25,7 & 1,3 & - \\
\hline Produtividade por trabalhador (R\$ mil) & 74,1 & 44,3 & 10,0 & - \\
Remuneração Média (R\$ / mês) & 1254 & 749 & 431 & - \\
Anos de Estudo (média nas firmas) & 9,13 & 7,64 & 6,89 & 100,0 \\
Gastos em P\&D Nacionais & 31,0 & 60,3 & 8,7 & 100,0 \\
Gastos em P\&D Estrangeira & 71,9 & 27,7 & 0,4 & - \\
\hline Exportações (US\$ milhões) & 11,4 & 2,1 & 0,0 & - \\
Importações (US\$ milhões) & 12,0 & 1,8 & 0,0024 & - \\
Coeficiente de Exportação (\% do Fat.) & 0,11 & 0,21 & 0,0 & - \\
Coeficiente de Importação (\% do Fat.) & 0,15 & 0,1 & 0,01 & - \\
\hline
\end{tabular}

Obs: Firmas Inovadoras: Inovam, diferenciam produtos e exportam com preço-prêmio; Firmas Padronizadas: Especializadas em produtos padronizados e exportam e/ou têm elevada produtividade; Firmas Competitivas: Não diferenciam produtos, não exportam e têm produtividade menor.

Fonte: De Negri e Salermo (2005).

A tipologia de firmas que organiza a Tabela 1 reflete as capacidades inovadoras e exportadoras de cada firma dentro do seu setor industrial. As firmas inovadoras são aquelas que inovam em produto (lançam produto novo no mercado) e exportam com diferencial de preços (preços nas exportações 30\% acima da média setorial e ou possuem produtividade significativamente superior à média setorial). As firmas com produtos padronizados não inovam em produto, podem inovar em processo, mas exportam sem preço-prêmio. As firmas competitivas não exportam e, regra geral, não inovam em produto e nem mesmo em processo.

Em síntese: (a) As firmas inovadoras são price-makers, exportam produto diferenciado e usufruem preço-prêmio nas exportações; (b) As firmas padronizadas são pricetakers, exportam produtos homogêneos e não usufruem preço-prêmio nas exporta- 
ções; (c) As firmas competitivas são price-takers, não exportam e raramente inovam em produto ou processo. $\mathrm{Na}$ amostra utilizada nesse estudo, $26 \%$ da transformação industrial é das firmas inovadoras, $66 \%$ das firmas padronizadas e aproximadamente $8 \%$ de firmas competitivas.

Deve ser ressaltado que as bases de dados utilizadas nessa pesquisa subestimam a importância das firmas competitivas na indústria brasileira. Essas bases de dados possuem informações somente para as empresas com mais de 20 trabalhadores; assim, as pequenas firmas que respondem por uma relevante parcela da produção industrial ficam excluídas da pesquisa. Portanto, o leitor deve considerar o comportamento das firmas competitivas como uma proxy de uma produção industrial com pequena escala, que não alcança os mercados externos, são intensivas em mão-de-obra pouco qualificada e empregam tecnologias convencionais. A Tabela 1 sumariza a estrutura industrial composta por essas firmas. ${ }^{3}$

\subsection{Uma Segmentação Inicial dos Espaços Industriais}

Uma forma de destacar as diferenças nos espaços ocupados pelas empresas industriais é separar os municípios em grupos com presença e ausência de empresas industriais. A Tabela 2 apresenta esses agrupamentos e os Gráficos 1 e 2 mostram uma primeira medida de concentração espacial da produção industrial. Na construção dos gráficos, os indicadores foram ordenados do maior para o menor, e foi calculada a sua contribuição para o total. Assim, quanto mais próxima a curva do eixo x (participação acumulada), menor a participação e concentração relativa desse indicador. Estes gráficos representam curvas de Lorenz invertidas, uma construção simples que indica quanto cada fração (número) de municípios detém do indicador representado.

O Gráfico 1 mostra que 200 municípios concentram aproximadamente $83 \%$ do valor bruto da transformação industrial (VTI), enquanto o Gráfico 2 mostra que esses 200 municípios concentram aproximadamente $97 \%$ do VTI das empresas inovadoras. Se o corte for origem de capital, as firmas estrangeiras mostram-se significativamente mais concentradas que as firmas nacionais.

A Tabela 2 apresenta alguns indicadores do espaço econômico ocupado pelas firmas industriais, segmentado ainda por firmas nacionais, estrangeiras e inovadoras. Os dados compilados nessa tabela representam o cruzamento da localização municipal das firmas com indicadores socioeconômicos desses municípios. As firmas industriais estão distribuídas em $46 \%$ dos municípios brasileiros, e estes municípios compõem

3 Vale ressaltar, portanto, que as aglomeraçôes que serão identificadas e avaliadas são aquelas compostas por firmas de grande porte. Aglomerações com firmas de pequeno porte, por maiores que essas sejam, não serão captadas nesse estudo, dadas as restrições postas pela base de dados utilizada. 
$82 \%$ da população brasileira e $93 \%$ da renda. Quanto às firmas nacionais, estas se distribuem por $45 \%$ dos municípios, que representam cerca de $81 \%$ da população brasileira e $93 \%$ da renda nacional. As firmas estrangeiras estão localizadas em apenas $10 \%$ dos municípios (549 cidades), onde estão $54 \%$ da população brasileira e $74 \%$ da renda nacional. Conseqüentemente, a renda per capita das áreas onde existem firmas estrangeiras é $19 \%$ superior à renda per capita das áreas ocupadas por empresas nacionais (LEMOS et al, 2005c).

GRÁFICO 1 - CONCENTRAÇÃO MUNICIPAL DE FIRMAS NACIONAIS E ESTRANGEIRAS (VTI)*

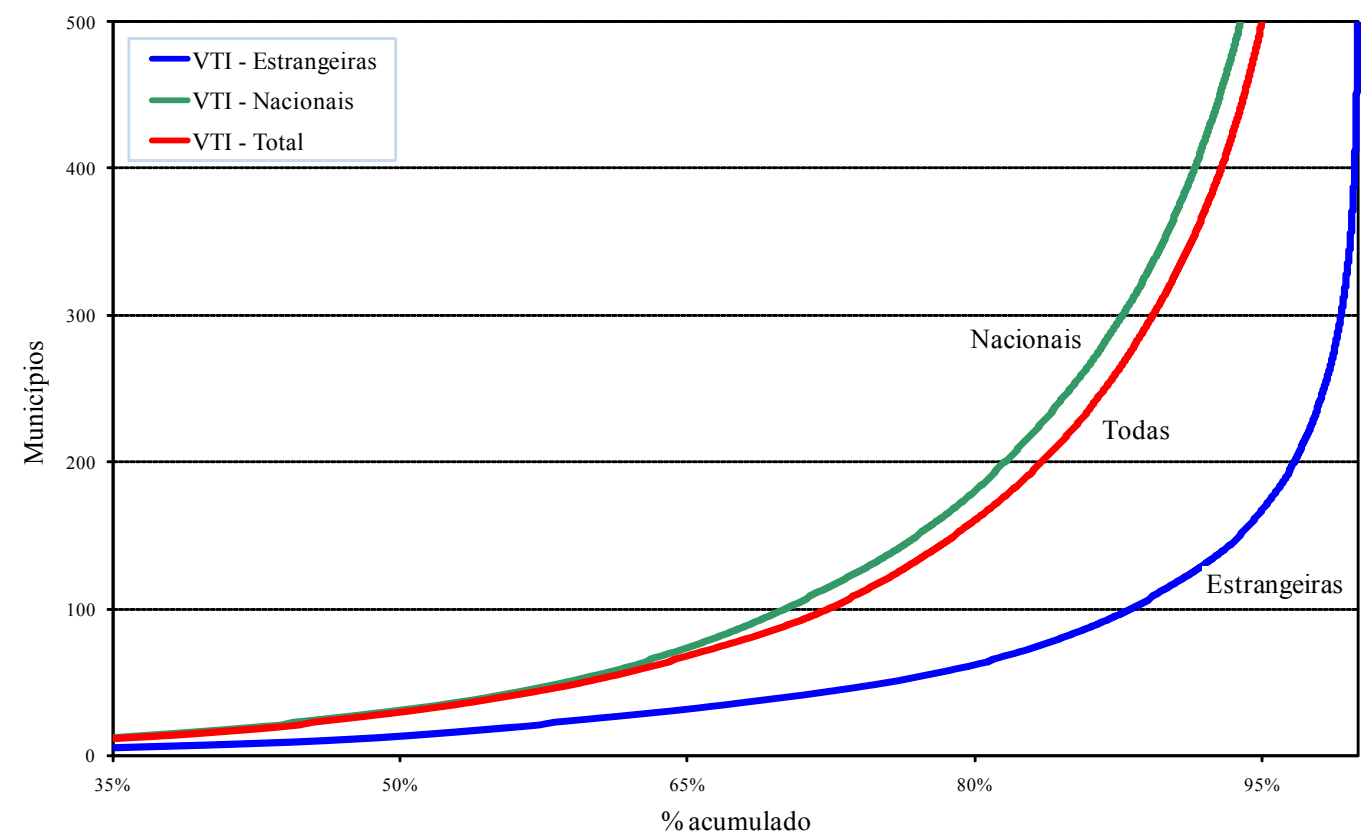

Nota: * Curvas de Lorenz invertidas: indicam quanto cada fração (número) de municípios detém do indicador representado.

Fonte: Lemos et al. (2005a) e Base Industrial Municipal (IPEA/CEDEPLAR). 


\section{GRÁFICO 2 - CONCENTRAÇÃO MUNICIPAL DE FIRMAS INOVADORAS NACIONAIS E ESTRANGEIRAS (VTI)*}

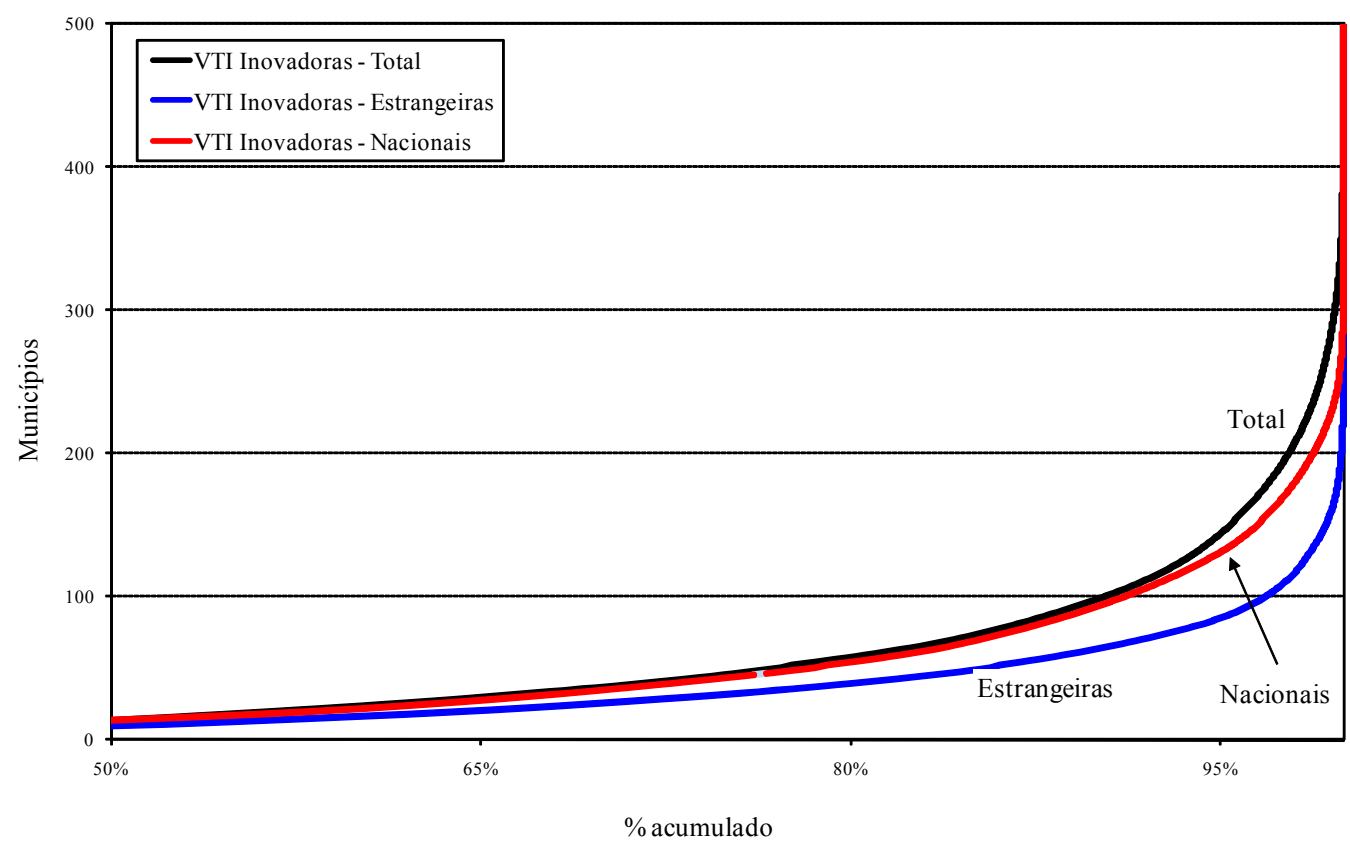

Nota: * Curvas de Lorenz invertidas: indicam quanto cada fração (número) de municípios detém do indicador representado.

Fonte: Lemos et al. (2005b e 2005c) e Base Industrial Municipal (IPEA/CEDEPLAR).

No que tange às dimensões tecnológicas e científicas (qualificação do mercado de trabalho, patentes e artigos científicos publicados, exclusive áreas de humanas e artes), a Tabela 2 mostra que as empresas inovadoras estão localizadas em municípios que concentram quase $80 \%$ da mão-de-obra qualificada e mais de $90 \%$ dos artigos e patentes. No conjunto dos municípios onde não existem empresas estrangeiras, estão apenas $8,6 \%$ das patentes e $6,4 \%$ dos artigos acadêmicos. Há, portanto, uma forte associação entre base tecnológica e a localização industrial. Os indicadores de capacitação tecnológica local, educação e renda, assim como vários outros indicadores de infra-estrutura municipal, seguem esse mesmo padrão de segregação e aglomeração espacial (DOMINGUES; RUIZ, 2005). ${ }^{4}$

4 Para detalhes sobre a seleção de artigos e patentes, ver Albuquerque et al. (2002). 
TABELA 2 - OS ESPAÇOS DAS FIRMAS INDUSTRIAIS NACIONAIS, ESTRANGEIRAS E INOVADORAS (2000)

\begin{tabular}{|c|c|c|c|c|c|c|c|c|}
\hline \multirow{2}{*}{ 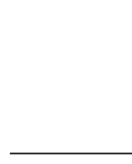 } & \multirow{2}{*}{ Tipo de firmas } & \multicolumn{7}{|c|}{ Características municipais do espaço ocupado e não ocupado pelas firmas } \\
\hline & & $\begin{array}{l}\text { Municípios } \\
\text { (\% do total) }\end{array}$ & $\begin{array}{c}\text { Educação } \\
\text { (1) }\end{array}$ & $\begin{array}{l}\text { Patentes } \\
\text { (2) }\end{array}$ & $\begin{array}{l}\text { Artigos } \\
\text { (2) }\end{array}$ & $\begin{array}{c}\text { População } \\
\text { (2) }\end{array}$ & $\begin{array}{l}\text { Renda } \\
\text { (3) }\end{array}$ & $\begin{array}{c}\text { Renda } \\
\text { Total } \\
\text { (4) }\end{array}$ \\
\hline \multirow{6}{*}{$\begin{array}{l}\text { Espaço } \\
\text { ocupado } \\
\text { pelas } \\
\text { firmas }\end{array}$} & Todos os tipos & 45,7 & 96,5 & 99,2 & 98,7 & 81,6 & 339 & 93,1 \\
\hline & Nacionais & 44,7 & 96,3 & 99,1 & 98,7 & 81,2 & 340 & 92,8 \\
\hline & Estrangeiras & 10,0 & 82,0 & 91,4 & 93,6 & 54,4 & 405 & 74,2 \\
\hline & Inovadoras & 8,4 & 78,6 & 90,3 & 93,4 & 50,0 & 420 & 70,5 \\
\hline & Inovadora Nacional & 5,8 & 71,3 & 85,6 & 89,9 & 43,3 & 437 & 63,5 \\
\hline & Inovadora estrangeira & 5,1 & 71,7 & 83,0 & 90,7 & 42,2 & 444 & 63,0 \\
\hline \multirow{6}{*}{$\begin{array}{l}\text { Espaço } \\
\text { não } \\
\text { ocupado } \\
\text { pelas } \\
\text { firmas }\end{array}$} & Todos os tipos & 54,3 & 3,5 & 0,8 & 2,3 & 18,4 & 111 & 6,9 \\
\hline & Nacionais & 55,3 & 3,7 & 0,9 & 2,3 & 18,8 & 114 & 6,2 \\
\hline & Estrangeiras & 90,0 & 18,0 & 8,6 & 6,4 & 45,6 & 168 & 25,8 \\
\hline & Inovadoras & 91,6 & 21,4 & 9,7 & 6,4 & 50,0 & 176 & 29,5 \\
\hline & Inovadora Nacional & 94,2 & 28,7 & 15,4 & 10,1 & 56,7 & 191 & 36,5 \\
\hline & Inovadora estrangeira & 94,9 & 28,3 & 7,0 & 10,3 & 57,8 & 191 & 37,0 \\
\hline
\end{tabular}

Notas: (1) \% da população acima de 25 anos com mais de 12 anos de estudos nos municípios selecionados.

(2) \% do total nacional nos municípios selecionados.

(3) Renda mensal per capita (R\$) nos municípios selecionados.

(4) \% da renda domiciliar nacional nos municípios selecionados.

Fonte: Lemos et al. (2005a, 2005b e 2005c), Domingues e Ruiz (2005) e Base Industrial Municipal.

Em suma, a presença da indústria em uma localidade está associada a um maior nível de renda per capita, uma infra-estrutura urbana melhor e um mercado de trabalho mais qualificado. Em segundo lugar, essas relações são ainda mais fortes na presença de empresas estrangeiras: os espaços ocupados pelas firmas estrangeiras são mais estruturados e ricos que aqueles ocupados pelas firmas nacionais. Entretanto, quando o espaço industrial é segmentado pelo critério inovação, nota-se que a origem de capital não é um determinante locacional relevante. As empresas inovadoras nacionais e estrangeiras ocupam espaços econômicos similares. Até aqui não há como concluir se o espaço econômico determina a localização da indústria ou se é a localização da indústria que determina e molda o espaço econômico. Essa é uma questão que requer estudos de causalidade, provavelmente envolvendo dados para vários períodos e que deve incorporar outros fatores na análise, como políticas públicas. O escopo deste artigo, entretanto, não é esse, e os dados disponíveis não permitem um estudo consistente sobre esse polêmico e relevante tema sobre causalidade no desenvolvimento regional. 


\section{ANÁLISE EXPLORATÓRIA ESPACIAL}

A análise exploratória espacial (ESDA) faz uso de dados georreferenciados para tentar descrever e visualizar padrões espaciais. A ESDA visa principalmente identificar e descrever distribuições espaciais, identificar localidades atípicas (outliers espaciais), agrupamentos de observações semelhantes (clusters) e identificar formas de heterogeneidade espacial (ANSELIN, 1998). A ESDA é útil no estudo dos processos de difusão espacial porque identifica padrões de autocorrelação espacial (homogeneidade).

A presença de autocorrelação espacial nos dados é medida usualmente através de estatísticas globais como Moran's I e Geary's C. Essas estatísticas globais, no entanto, ignoram a existência de padrões locais de autocorrelação espacial, podendo levar a resultados enganosos sobre a existência de autocorrelação espacial nos dados (ANSELIN, 1995). Esse trabalho utiliza o instrumental analítico desenvolvido por Anselin (1995;1996), as estatísticas LISA (Local Indicators of Spatial Association), para detectar padrões locais de autocorrelação espacial nas variáveis.

As estatísticas do tipo LISA fazem a decomposição de indicadores globais em indicadores locais permitindo avaliar a contribuição individual de cada observação para a estatística global. Assim, a soma dos indicadores locais é proporcional ao indicador global de associação espacial. A maioria das estatísticas espaciais globais pode ser decomposta em estatísticas locais. Neste trabalho, utiliza-se a estatística local denominada Moran Local, desenvolvida por Anselin (1995) e derivada da estatística global "I" de Moran (Moran’s I). A estatística LISA é um indicador da significância e do sentido da autocorrelação espacial. É definida para cada observação em função da média dos vizinhos.

A forma básica para o LISA para a região $i$ é:

$$
\sum_{j=1}^{N} w_{i j} \operatorname{sim}_{i j}
$$

$\operatorname{sim}_{i j}$ : medida da similaridade entre observações das regiões $i$ e $j$.

O LISA empregado neste trabalho é a versão local do Moran's I, definido na região $i$ como:

$$
I_{i}=\sum_{j=1}^{N} w_{i j} \operatorname{sim}_{i j}=\sum_{j=1}^{N} w_{i j}\left(Y_{i}-\bar{Y}\right)\left(Y_{j}-\bar{Y}\right)=\left(Y_{i}-\bar{Y}\right) \sum_{j=1}^{N} w_{i j}\left(Y_{j}-\bar{Y}\right)
$$


A construção do LISA se dá através da estimação da correlação do valor padronizado (desvio da média global) da variável $x$ do município $i$ em relação ao valor padronizado da variável $x$ do vizinho $j$. A construção deste índice para cada um dos municípios permite a identificação de aglomerações no território. A incidência das aglomerações depende da significância estatística adotada no teste de autocorrelação espacial.

Assim, autocorrelação espacial positiva significa valores similares (altos ou baixos) à média dos vizinhos para uma determinada observação, evidenciando a presença de clusters de altos (high-high) e/ou baixos (low-low) valores para as variáveis. Por outro lado, a autocorrelação espacial negativa indica valores significativamente mais altos (ou baixos) para a observação quando comparados à média dos vizinhos (bigh-low ou low-high), evidenciando a presença de observações atípicas (outliers espaciais). Neste trabalho, o nível de significância escolhido para o LISA foi de $10 \%$. A matriz de vizinhança utilizada foi construída selecionando os 20 municípios vizinhos mais próximos de cada município, com peso proporcional a $l /\left(d_{i j}\right)^{2}$, onde $d_{i j}$ é a distância entre as sedes dos municípios vizinhos. A distribuição dos municípios segundo a Análise Espacial divide-os em quatro tipos de articulação espacial:

(a) Locais com elevada Renda (PIB) e alta correlação positiva com seus vizinhos (High-High);

(b) Locais com elevada Renda (PIB) e correlação negativa com seus vizinhos (HighLow);

(c) Locais com baixa Renda (PIB) e alta correlação positiva com seus vizinhos (LowLow);

(d) Locais com baixa Renda (PIB) e alta correlação negativa com seus vizinhos (Low-High).

Os mapas das Figuras 2 e 3 apresentam os resultados da autocorrelação espacial para as regiões em estudo, tanto para o PIB municipal como para a renda (mapas a e b). Os mapas c e d apresentam o mesmo exercício de correlação espacial, mas para o logaritmo das variáveis. Em todos os mapas, as áreas escuras representam regiões de forte aglomeração de PIB e renda. No contorno dessas áreas observa-se um padrão low-high, ou seja, áreas de municípios com baixo PIB e renda, vizinhos de municípios com PIB e renda elevados. Esse padrão é visível no entorno das capitais estaduais, com exceção de Florianópolis para o PIB. Em São Paulo já se observa uma destacada interiorização com uma forte conexão com áreas do interior do Estado. Para as outras regiões metropolitanas, as "manchas" aparecem isoladas. 
Os mapas da concentração econômica para o logaritmo da renda e do PIB (c e d) permitem explorar a variação destes indicadores ao longo do território, numa analogia aos modelos de crescimento no tempo. Como o LISA é a diferença entre a estatística média e a do município, tomada em logaritmo essa diferença explicita se há variação percentual significativa entre observações próximas. A utilidade desses mapas está na capacidade de atenuar os efeitos indicadores muito altos, ou muito baixos, que tendem a não se correlacionar com a média dos vizinhos. Mapas de correlação no logaritmo das variáveis tendem a revelar "manchas" de correlação espacial maiores do que os mapas no nível das variáveis.

Assim, se nos deslocamos pelas áreas mais escuras (bigh-high) do mapa (c), caminhamos por uma área de baixa variação espacial (relativa) da renda municipal. Ao nos deslocarmos de uma área escura para uma área cinza (low-high), encontramos maior variação da renda municipal ou do PIB (mapa d). Em termos gerais, as áreas de correlação espacial no mapa da renda são menores do que no mapa do PIB, indicando que a concentração espacial da renda é mais significativa.

Os mapas tornam visível a extensão da homogeneidade da distribuição espacial da renda no Estado de São Paulo: a área escura prolonga-se do litoral paulista pelo interior de São Paulo, chegando ao Triângulo Mineiro. No eixo São Paulo-Rio de Janeiro-Vitória, ao longo da BR-101, parece ocorrer também uma área de relativa homogeneidade da renda e do PIB.

O eixo Curitiba-Joinvile é outra região de destaque nos mapas (c) e (d), com uma interiorização mais significativa no Estado do Paraná. A área metropolitana de Porto Alegre-Caxias é outro exemplo de região de concentração e relativa homogeneidade espacial da atividade econômica no sul do País, embora sua extensão seja menor que as áreas no Paraná e Santa Catarina. A área de padrão high-high no sul do Rio Grande do Sul capta um padrão de homogeneidade ao longo da fronteira, embora não se possa diferenciar, pelo mapa, as diferenças de nível entre esta área e a RM de Porto Alegre. ${ }^{5}$

Os mapas da Figura 3 apresentam os indicadores de correlação espacial no Nordeste. Apresentam-se áreas relativamente homogêneas no interior do Ceará, de Pernambuco e da Bahia, onde a produção e a riqueza se difundiriam em alguma medida para o interior estadual (Figuras 3c e 3d). O destaque na interiorização do Nordeste é a área de Petrolina-Juazerio, localizada majoritariamente no interior da Bahia - no entorno do rio São Francisco - mas intensamente conectada à economia de Pernambuco, pos-

5 Este resultado também decorre da característica da matriz de pesos-vizinhança nas áreas de fronteira do mapa, pois os "vizinhos mais próximos" são nesses casos necessariamente os que se distribuem ao longo dessa linha. 
suindo uma extensão que pode abarcar até mesmo o sul do Ceará. Já nos Estados do Maranhão, Piauí, Rio Grande do Norte, Alagoas, Sergipe e Paraíba é observado um padrão de concentração no entorno das capitais, sem nenhuma extensão ao interior. Essas "fraturas" no processo de integração intra-estadual dificultam a integração regional estadual e amplificam a polarização estadual. Para finalizar, vale observar que as escalas das aglomerações nordestinas e suas extensões para o interior são significativamente menores que as verificadas no Sul-Sudeste. Logo, essa interiorização é ainda mais frágil que a verificada nos Estados do Sul e Sudeste.

FIGURA 2- AGLOMER AÇÕES DA RENDA E DA PRODUÇÃO NO SUL E SUDESTE* (2000)

(a) Renda

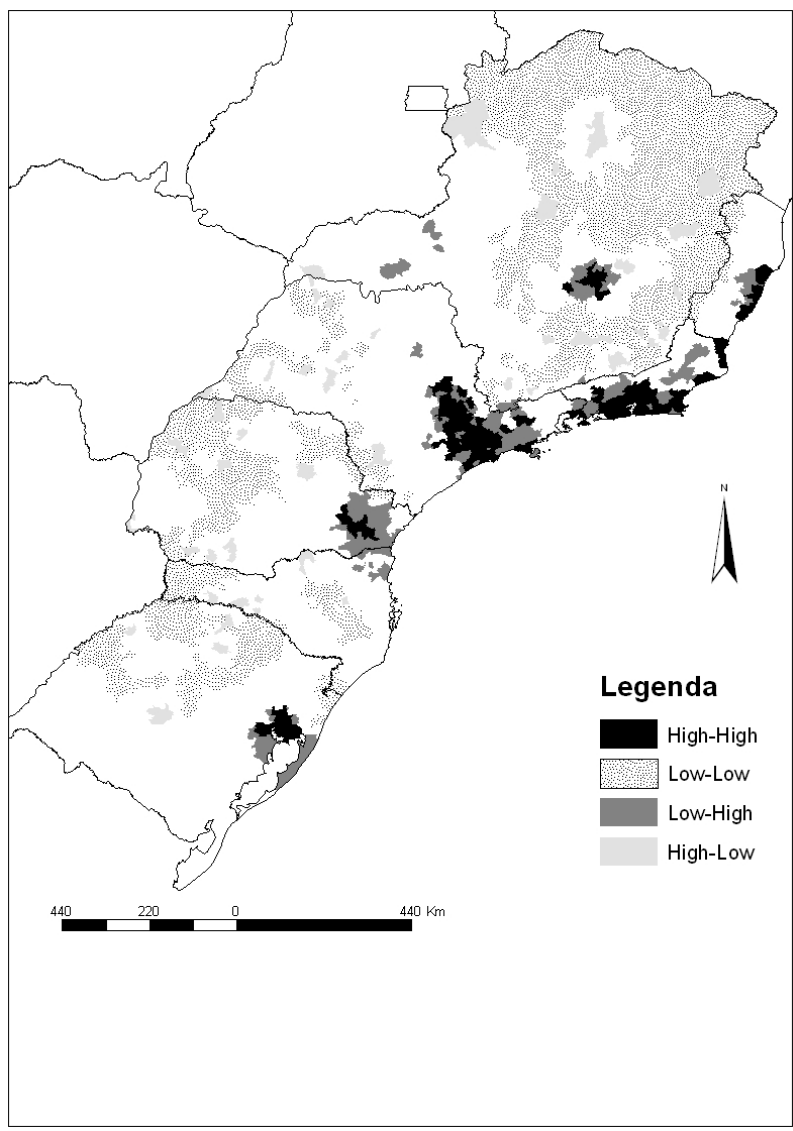


(b) PIB

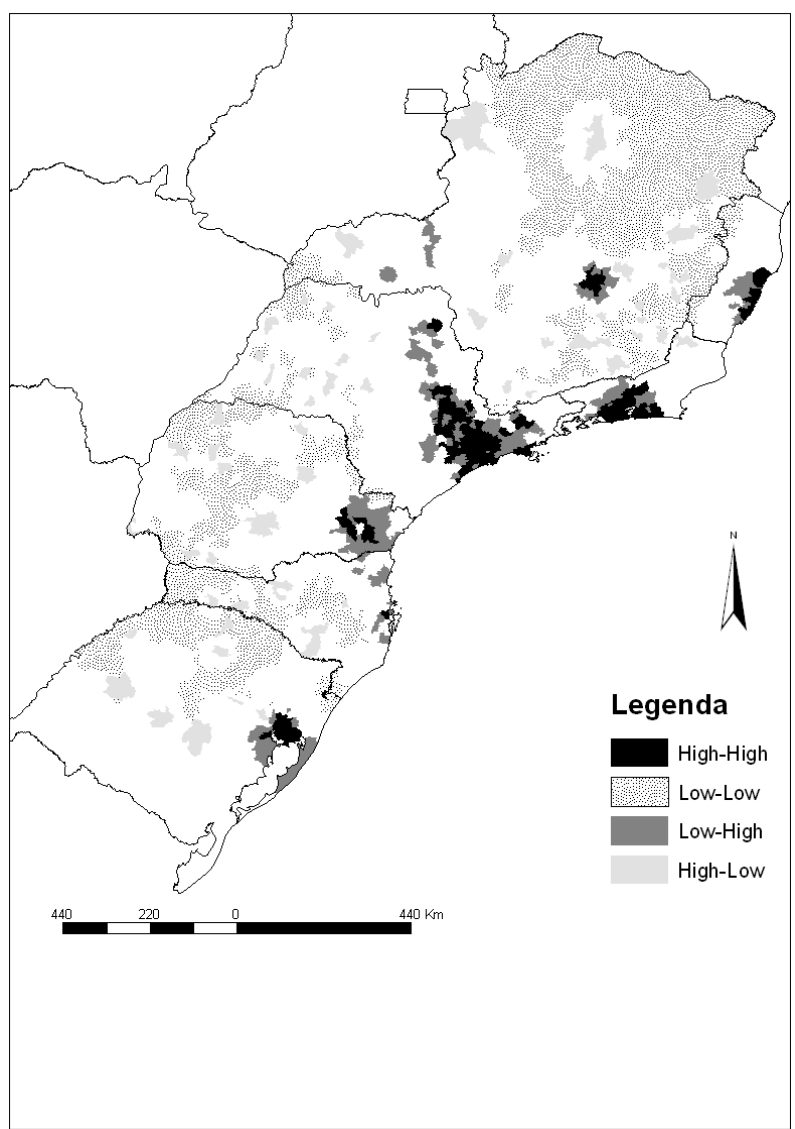


(c) Renda (log)

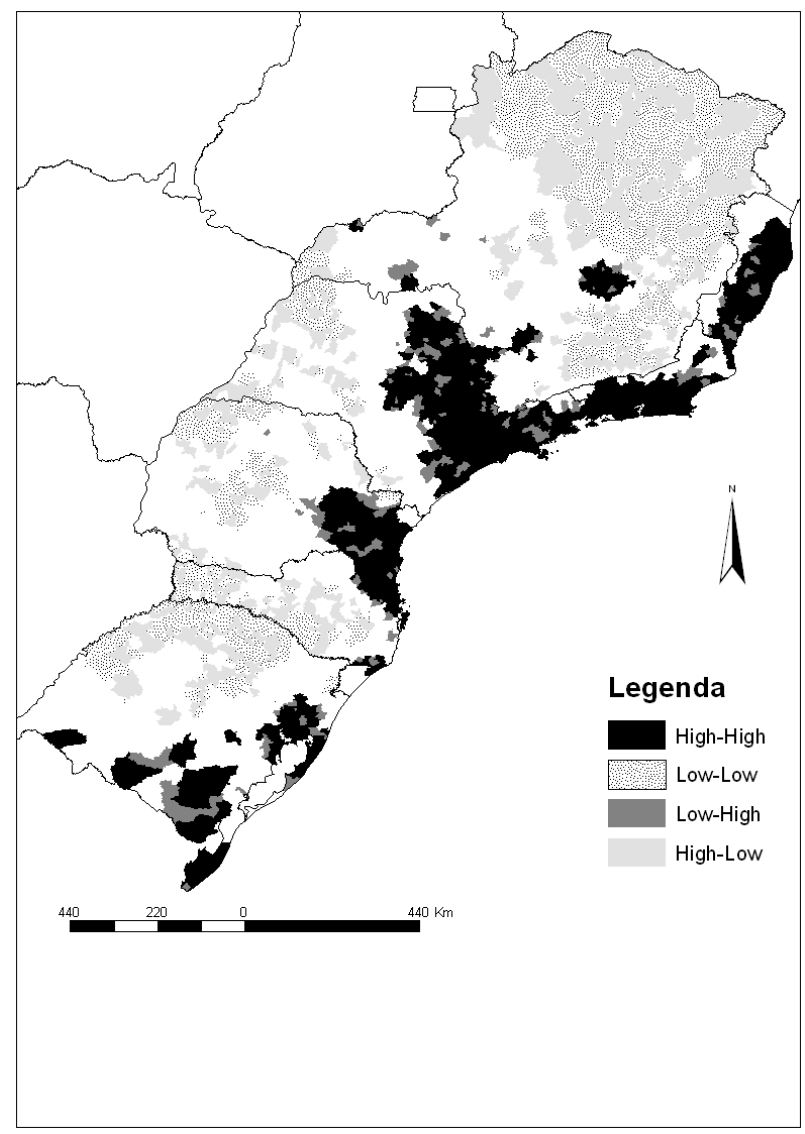


(d) PIB $(\log )$

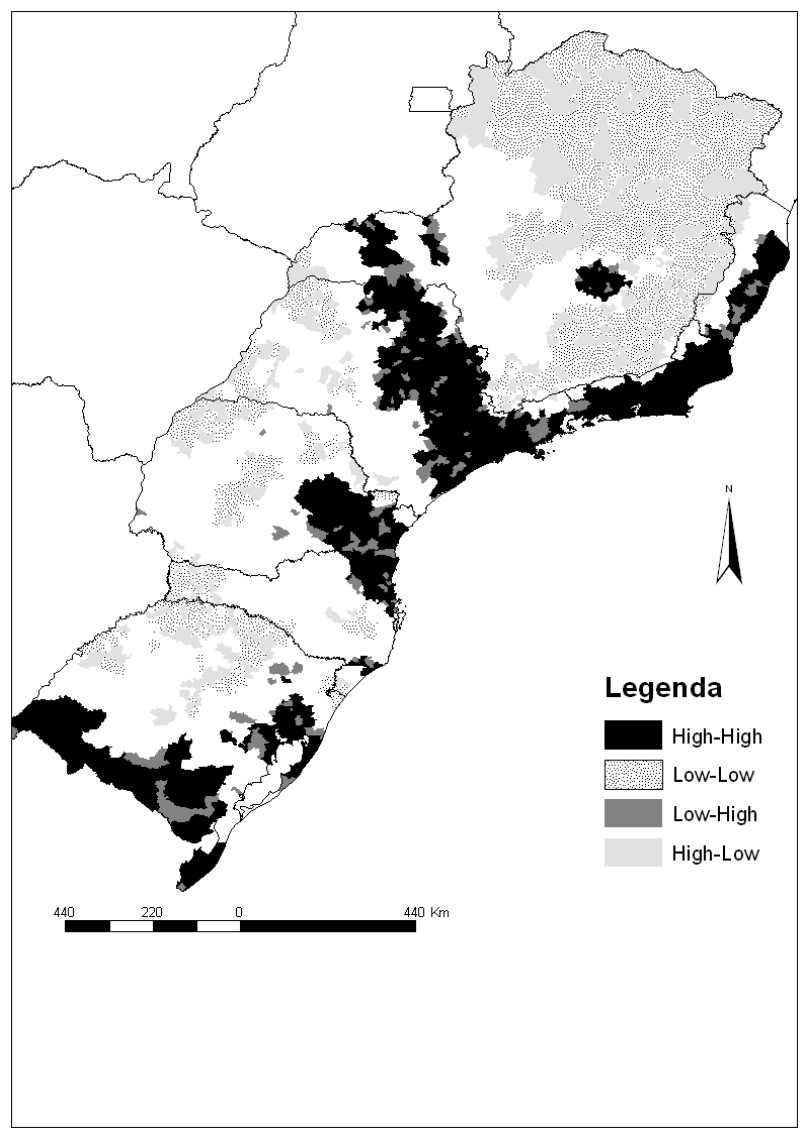

Nota: *indicadores LISA de correlação espacial local.

Fonte: Elaboração própria a partir de Lemos et al. (2005a) e Base Industrial Municipal (IPEA/ CEDEPLAR). 
FIGURA 3- AGLOMER AÇÕES DA RENDA E DA PRODUÇÃO NO NORDESTE (2000)

(a) Renda

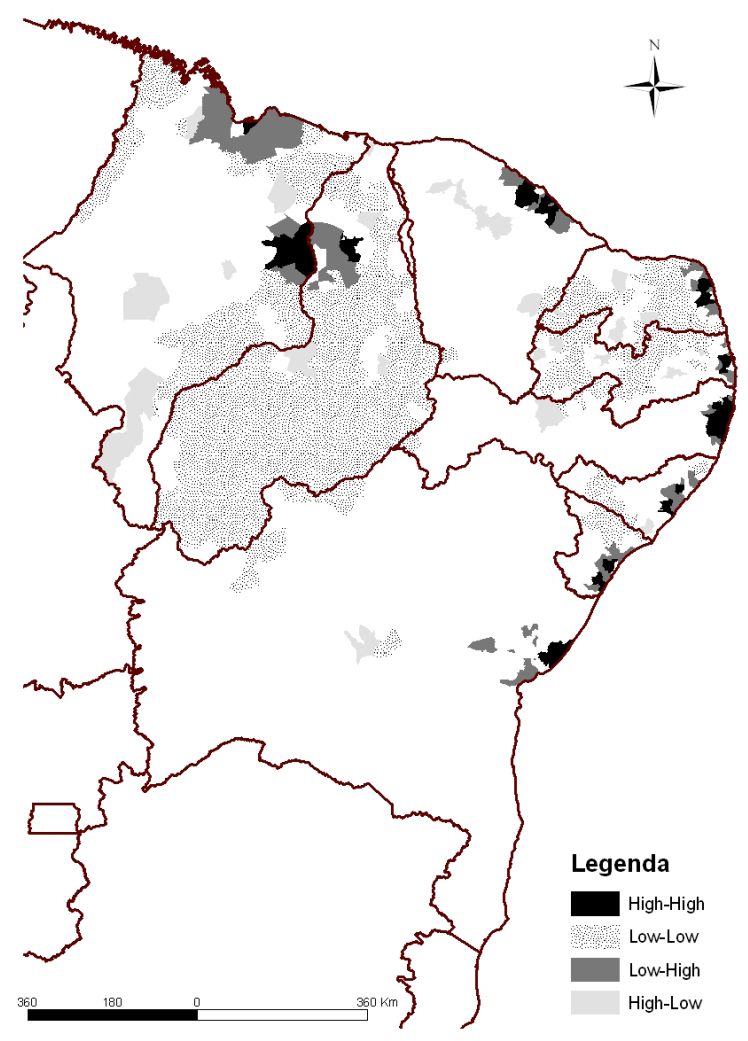


(b) PIB

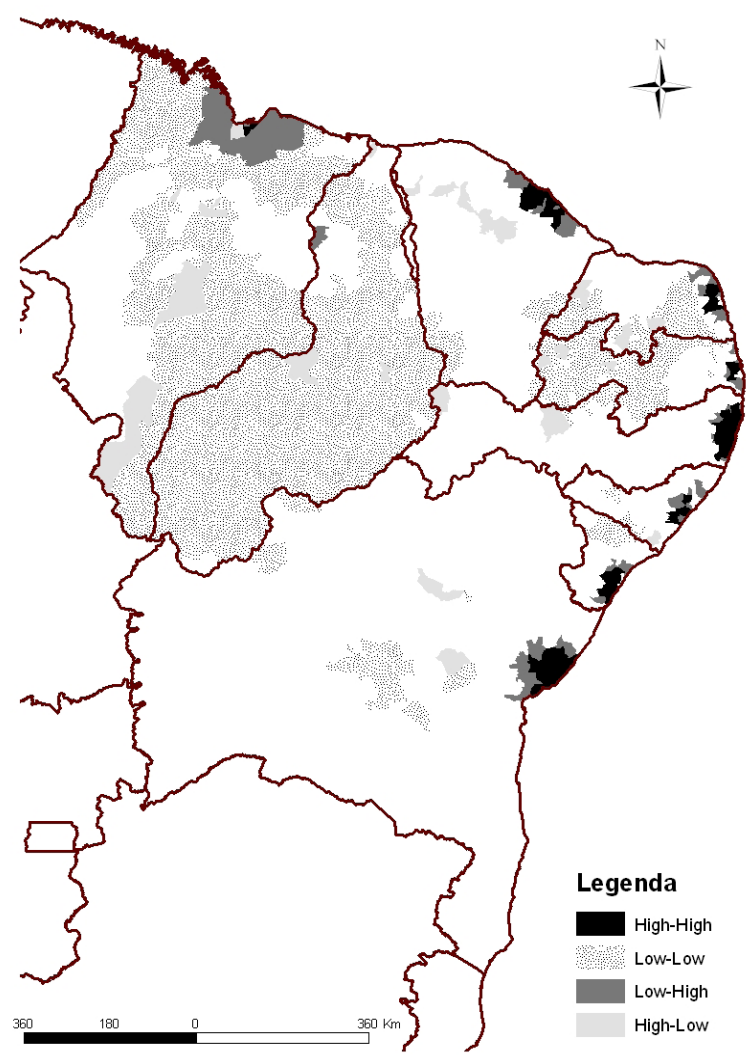


(c) Renda (log)

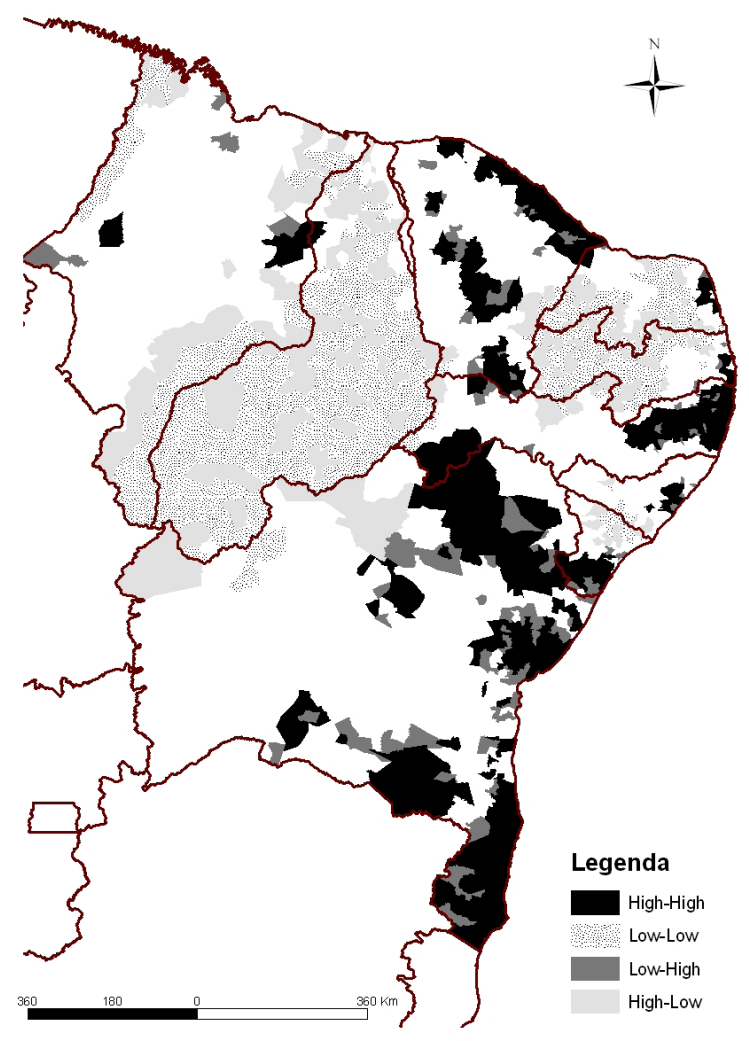


(d) PIB $(\log )$

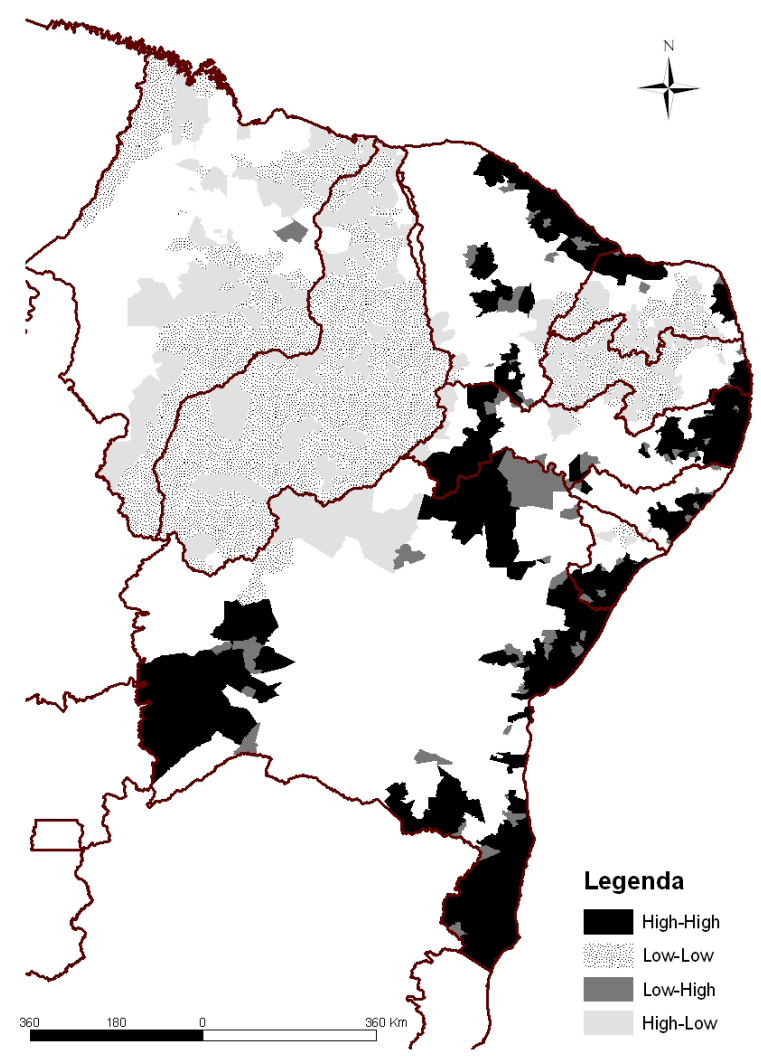

Nota: *indicadores LISA de correlação espacial local.

Fonte: Elaboração própria a partir de Lemos et al. (2005a) e Base Industrial Municipal (IPEA/ CEDEPLAR).

\section{ANÁLISE ECONOMÉTRICA ${ }^{6}$}

Nesta seção, uma análise econométrica espacial será implementada para identificar os fatores que estruturam as aglomerações econômicas espaciais identificadas nas Figuras 2 e 3 . O objetivo é delimitar a importância de cada um desses fatores e discutir o potencial de expansão das aglomerações.

Os modelos de econometria espacial mais utilizados permitem distinguir dois tipos de correlação espacial, que se traduzem em efeitos multiplicadores globais e locais. Os efeitos globais são especificados na forma de modelos SAR (modelos autorregressivos espaciais) e os efeitos locais na forma de modelos SMA (média móvel espacial).

6 Parte desta seção tem como referência Lemos et al. (2005a). 
Não entraremos em detalhes sobre modelos SMA porque o programa utilizado para estimação dos modelos nesse trabalho (Spacestat) não inclui estimação desses tipos de modelos (ANSELIN, 1999).

Os dois modelos SAR mais freqüentemente utilizados em econometria espacial são o modelo de erro autorregressivo espacial e o modelo de defasagem espacial. A dependência espacial global nos termos de erro é incorporada no modelo por meio de termos de erro autorregressivos espaciais da seguinte forma:

$$
\begin{aligned}
& Y=X \beta+\varepsilon \\
& \varepsilon=\lambda W \varepsilon+u \\
& Y=X \beta+(I-\lambda W)-1 u
\end{aligned}
$$

Onde $\varepsilon$ é o termo de erro autocorrelacionado e u é um termo de erro i.i.d. Constatase, através das equações 2 e 3 , que o modelo de erro espacial é um caso de regressão com erros não esféricos onde a estrutura da dependência espacial é expressa na matriz de variâncias e co-variâncias dos erros (equação 4).

$$
\begin{aligned}
& E\left[\varepsilon \varepsilon^{\prime}\right]=\sigma 2\left[(I-\lambda W)-1(I-\lambda W)-I^{\prime}\right] \\
& {[I-\lambda W]-1=I+\lambda W+\lambda 2 W 2+\lambda 3 W 3+\ldots}
\end{aligned}
$$

O modelo de erro espacial é apropriado quando as variáveis não incluídas no modelo e presentes nos termos de erro são autocorrelacionadas espacialmente. Os efeitos globais no modelo de erro SAR são evidenciados na matriz de variâncias e co-variâncias dos erros em (equação 4) e na forma reduzida do modelo (equação 3).

A expansão da inversa $(I-\lambda W)-1$ para $|\lambda|$ e $W<1$ (equação 5) mostra que a correlação é maior para os vizinhos mais próximos e decresce continuamente em direção aos vizinhos mais distantes. Esse tipo de correlação é denominado global, uma vez que contempla todas as localidades e implica a existência de um multiplicador global associado aos termos de erro i.i.d.. Assim, um choque em u, ou seja, numa variável qualquer não incluída no modelo, vai ser transmitido para todas as outras no sistema. O modelo de defasagem espacial é especificado da seguinte forma:

$$
\mathrm{Y}=\rho \mathrm{Wy}+\mathrm{X} \beta+\varepsilon
$$

Onde $W$ é a matriz de pesos espaciais; $X$ é a matriz de variáveis independentes; $\beta$ é o vetor de coeficientes das variáveis independentes; $\rho$ é o coeficiente espacial au- 
torregressivo e $\varepsilon$ é o termo de erro. A inclusão de $W y$ como variável explicativa no modelo 6 significa que valores da variável y na localidade i estão relacionados aos valores dessa variável nas localidades vizinhas. O método de estimação desse modelo precisa levar em conta essa endogeneidade da variável Wy (ANSELIN, 1999). Uma interpretação mais precisa do modelo 6 é evidenciada na sua forma reduzida:

$$
Y=(I-\rho W)^{-1} X \beta+(I-\rho W)^{-1} \varepsilon
$$

A expansão $(I-\rho W)^{-1}$ inclui tanto as variáveis explicativas quanto os termos de erro. Assim, a interpretação econômica da relação de causalidade $y_{j} \rightarrow y_{i}$ pode ser considerada como sendo o resultado de um processo que envolve correlação espacial global nas variáveis explicativas e nos termos de erro. Isso implica que choques em uma localidade afetam todas as outras através de um efeito multiplicador global, associado tanto às variáveis explicativas incluídas no modelo quanto às excluídas - e presentes nos termos de erro. A forma reduzida do modelo de defasagem espacial mostra que a matriz de pesos $W y$ é correlacionada com os termos de erro mesmo quando esses são i.i.d. (ANSELIN, 1999).

Além das duas especificações mencionadas, quando os testes assim indicavam foi utilizada uma terceira especificação: SARSAR (ou SARMA), que representa uma combinação das duas anteriores (modelo de erro e de defasagem espacial).

As conseqüências de se ignorar a autocorrelação espacial nos modelos de regressão dependem da hipótese alternativa. Se a hipótese alternativa for o modelo de defasagem espacial, o estimador dos mínimos quadrados ordinários (MQO) será enviesado e inconsistente. Por outro lado, caso a hipótese alternativa seja o modelo de erro espacial, as conseqüências serão idênticas à da autocorrelação serial dos resíduos. Nesse caso, embora a estimação pelos MQO produza coeficientes não enviesados, as estimativas dos desvios padrão serão inconsistentes. Isso faz com que as estatísticas $t$ e $F$ sejam inadequadas e o $R^{2}$ incorreto.

Os modelos foram estimados pelo programa SpaceStat versão 1.80 (Anselin, 2001). Os métodos de estimação para o modelo de erro espacial disponíveis no SpaceStat são os seguintes: máxima verossimilhança, mínimos quadrados ponderados espacialmente (WLS espacial - iterativo), e método dos momentos generalizados (GM - 2 estágios e GM - interativo). As duas alternativas de estimação pelo método dos momentos são robustas para não normalidade dos erros. Os métodos disponíveis no SpaceStat para estimação do modelo de defasagem espacial são máxima verossimilhança e variáveis instrumentais - VI (2SLS, Robusto e Bootstrap). As estimações por VI-Robusto e VI-Bootstrap são alternativas ao 2SLS para não normalidade dos resíduos e heterocedasticidade. 
Uma vez que a análise dos resíduos em todos os modelos evidenciou fortes indícios de não normalidade, os modelos de defasagem espacial (indicados pelos testes de especificação) foram estimados pelo VI-Robusto. Ressalta-se que tanto o método dos momentos generalizados quanto o das variáveis instrumentais são reconhecidamente métodos pouco eficientes, embora consistentes. Entretanto, se por um lado a característica de baixa eficiência desses métodos aumenta a probabilidade de aceitação da hipótese nula nos testes de significância individual dos coeficientes, por outro lado a menor eficiência pode se constituir numa vantagem, uma vez que as variáveis significativas realmente o são no pior cenário possível.

A matriz $\mathrm{W}$ utilizada neste trabalho foi construída selecionando os 20 municípios vizinhos mais próximos de cada município, com peso proporcional a $\mathrm{l} / d_{i j 2}$, onde $d_{i j}$ é a distância entre as sedes dos municípios. As variáveis dependentes são o PIB e Renda municipal e todas as variáveis utilizadas estão descritas no Quadro 1. Nos modelos, todas as variáveis foram utilizadas em logaritmo natural.

Os Anexos l e 2 apresentam a correlação (do logaritmo) destas variáveis para as duas regiôes em estudo. Como esperado, as correlações da população com a renda e o PIB são elevadas, assim como sua correlação com outras variáveis (depósitos a prazo e serviços). Assim, a opção foi não incluir a variável de população no modelo para evitar problemas de multicolinearidade. $\mathrm{O}$ sinal das correlações para as variáveis é o esperado, como os negativos para o custo de transporte, positivos para a indústria, educação, saneamento e patentes. A correlação da renda e do PIB com o PIB da agropecuária é a mais baixa entre as variáveis selecionadas. Um resultado interessante é a correlação positiva com a área, indicando que no espaço selecionado (relativamente homogêneo) o PIB e a renda são maiores nos municípios maiores (note-se que São Paulo, Rio de Janeiro, São José dos Campos e Campinas, municípios entre os 10 maiores PIBs do País, são cidades com área acima da média no Sul e Sudeste). 
QUADRO I - VARIÁVEIS MUNICIPAIS

\begin{tabular}{|lllc|}
\hline Código & & Ano & Fonte \\
\hline PIB & PIB Municipal (R\$ mil) & 2000 & IBGE \\
RENDA & Renda Municipal & 2000 & Censo \\
Depósito a Prazo & Depósitos a prazo $(\mathrm{R} \$ 1.000)$ & 2000 & SNIU \\
Saneamento & Domicílios com banheiro ligado a rede geral ou fossa séptica & 2000 & SNIU \\
Área & Área em km2 & 2000 & SIMBRASIL \\
Educação Superior & População + 25 anos com + 12 anos de estudo & 2000 & SIMBRASIL \\
Custo Transp.- SP & Custo de transporte para São Paulo (capital) & 1996 & IPEADATA \\
Custo Transp.- Capital & Custo de transporte para a Capital do Estado & 1996 & IPEADATA \\
Bens Intermediários & VTI do Setor de Bens Intermediários & 2000 & IPEA/Cedeplar \\
Bens Capital e Duráveis & VTI do Setor de Bens de Capital e Duráveis & 2000 & IPEA/Cedeplar \\
Bens de Consumo & VTI do Setor de bens de Consumo Não-Durável & 2000 & IPEA/Cedeplar \\
Ind. Extrativa & VTI do Setor de Extrativa & 2000 & IPEA/Cedeplar \\
Firmas Inovadoras & VTI das Firmas Padronizadas (+ 20 pessoas ocupadas) & 2001 & IPEA/Cedeplar \\
Firmas Padronizadas & VTI das Firmas Competitivas (+ 20 pessoas ocupadas) & 2002 & IPEA/Cedeplar \\
Firmas Competitivas & VTI das Firmas Inovadoras (+ 20 pessoas ocupadas) & 2003 & IPEA/Cedeplar \\
Patentes & Número de Patentes 1999+2000 & 2000 & Albuquerque \\
PIB Agropecuária & PIB Municipal - Agropecuária - R\$ mil & 2000 & (2002) \\
\hline
\end{tabular}

\subsection{Determinantes das Aglomerações Econômicas Espaciais no Sudeste}

A Tabela 3 apresenta o resultado de dois modelos para a renda municipal. As características da base industrial são altamente correlacionadas, o que impede a sua utilização conjunta no modelo. Assim, o primeiro modelo utiliza uma configuração usual da indústria pela característica de uso do produto (intermediários, capital e duráveis, de consumo e extrativos), enquanto a segunda emprega uma divisão da indústria por critérios de inovação e diferenciação de produto (firmas inovadoras, padronizadas e competitivas). Nos dois casos, as únicas variáveis não-significativas foram as de saneamento e PIB agropecuária. ${ }^{7} \mathrm{O}$ único coeficiente negativo foi para

$7 \mathrm{O}$ z-value do modelo de defasagem espacial é similar à estatística $t$ dos modelos de mínimos quadrados. Nos modelos estimados, estatísticas $z$ acima de 2,2 indicam significância acima de 3\%; estatísticas acima de 2,81 indicam significância acima de $5 \%$. 
o custo de transporte para a capital, o que indica que a renda é maior em espaços próximos às capitais estaduais, o que era visível no mapa de aglomeração.

Uma hierarquia da composição industrial e da renda municipal pode ser construída a partir dos coeficientes da base industrial. A presença da indústria de bens de capital e duráveis ou indústria inovadora é determinante de renda municipal mais elevada, relativamente a municípios com maior participação da indústria extrativa. Já firmas com menor conteúdo tecnológico e competitivas tendem a não gerar grandes concentrações de renda.

TABELA 3-MODELOS PARA A RENDA - SUL-SUDESTE

\begin{tabular}{|c|c|c|c|c|}
\hline \multicolumn{5}{|c|}{ Variável Dependente: RENDA } \\
\hline \multirow[b]{2}{*}{ Variável Independente } & \multicolumn{2}{|c|}{ Modelo 1} & \multicolumn{2}{|c|}{ Modelo 2} \\
\hline & Coeficiente & z-value & Coeficiente & z-value \\
\hline Constante & 12.348 & 46.30 & 12.455 & 46.21 \\
\hline Saneamento & 0.021 & 2.21 & 0.020 & 2.10 \\
\hline Área & 0.277 & 17.22 & 0.271 & 16.70 \\
\hline Educação Superior & 0.449 & 18.26 & 0.458 & 18.47 \\
\hline Custo de Transporte - SP & 0.008 & 0.19 & -0.002 & -0.06 \\
\hline Custo de Transporte - Capital & -0.197 & -7.70 & -0.206 & -7.97 \\
\hline Patentes & 0.102 & 19.39 & 0.014 & 21.66 \\
\hline Depósitos a Prazo & 0.039 & 19.01 & 0.025 & 19.06 \\
\hline PIB Agropecuária & 0.011 & 0.98 & 0.040 & 1.22 \\
\hline Serviços & 0.024 & 12.23 & 0.680 & 12.62 \\
\hline Bens Intermediários & 0.015 & 9.18 & - & - \\
\hline Bens de Capital e Duráveis & 0.027 & 12.13 & - & - \\
\hline Bens de Consumo & 0.018 & 11.49 & - & - \\
\hline Indústria Extrativa & 0.013 & 5.33 & - & - \\
\hline Firmas Inovadoras & - & - & 0.025 & 12.02 \\
\hline Firmas Padronizadas & - & - & 0.017 & 10.87 \\
\hline Firmas Competitivas & - & - & 0.018 & 10.64 \\
\hline LAMBDA & & 0.681 & & 0.680 \\
\hline Modelo & & SAR & & SAR \\
\hline № De Observações & & 2825 & & 2825 \\
\hline
\end{tabular}

Esse mesmo resultado é captado pelos dois modelos para o PIB municipal apresentado na Tabela 4. A presença da indústria de bens de capital e duráveis ou indústria inovadora é fator de PIB municipal mais elevado, relativamente a municípios com 
maior participação da indústria extrativa ou indústria competitiva. A primeira estimativa utiliza a configuração usual da indústria, enquanto a segunda emprega a divisão da indústria por critérios de inovação e diferenciação de produto. Todas as variáveis foram significativas a pelo menos $5 \%$ de significância. Os sinais dos coeficientes são os esperados (positivos) para educação superior, patentes, PIB agropecuária, depósitos a prazo e serviços. O único coeficiente negativo foi para o custo de transporte para a capital - como no modelo para a renda - e indica que o PIB é maior em espaços próximos às capitais estaduais. $\mathrm{O}$ coeficiente negativo para saneamento pode indicar que as áreas de concentração da atividade econômica, controlados os efeitos das demais variáveis, possuem pior infra-estrutura desse serviço urbanodomiciliar. Este resultado, diferente do obtido nos modelos da renda, indica uma possível "segmentação" em termos de saneamento entre as áreas de concentração de renda domiciliar e de produção econômica.

\section{TABELA 4 - MODELOS PARA O PIB - SUL-SUDESTE}

\begin{tabular}{|c|c|c|c|c|}
\hline \multicolumn{5}{|c|}{ Variável Dependente: PIB } \\
\hline \multirow[b]{2}{*}{ Variável Independente } & \multicolumn{2}{|c|}{ Modelo 1} & \multicolumn{2}{|c|}{ Modelo 2} \\
\hline & Coeficiente & z-value & Coeficiente & $z$-value \\
\hline Variável dependente defasada PIB & 0.207 & 10.216 & 0.204 & 10.417 \\
\hline Constante & 5.515 & 14.716 & 5.742 & 15.815 \\
\hline Saneamento & -0.020 & -2.819 & -0.025 & -3.477 \\
\hline Área & 0.164 & 11.580 & 0.159 & 11.275 \\
\hline Educação Superior & 0.263 & 10.747 & 0.269 & 11.418 \\
\hline Custo de Transporte - SP & 0.181 & 6.763 & 0.156 & 6.124 \\
\hline Custo de Transporte - Capital & -0.166 & -6.793 & -0.163 & -6.800 \\
\hline Patentes & 0.087 & 11.958 & 0.094 & 13.216 \\
\hline Depósitos a Prazo & 0.035 & 15.036 & 0.037 & 16.001 \\
\hline PIB Agropecuária & 0.090 & 6.207 & 0.090 & 6.305 \\
\hline Serviços & 0.033 & 14.086 & 0.033 & 14.517 \\
\hline Bens Intermediários & 0.022 & 10.800 & - & - \\
\hline Bens de Capital e Duráveis & 0.036 & 12.440 & - & - \\
\hline Bens de Consumo & 0.018 & 9.467 & - & - \\
\hline Indústria Extrativa & 0.014 & 4.233 & - & - \\
\hline Firmas Inovadoras & - & - & 0.042 & 14.176 \\
\hline Firmas Padronizadas & - & - & 0.025 & 13.535 \\
\hline Firmas Competitivas & - & - & 0.014 & 7.466 \\
\hline Modelo & \multicolumn{2}{|c|}{ LAG } & \multicolumn{2}{|c|}{ LAG } \\
\hline № de Observações & \multicolumn{2}{|c|}{2825} & \multicolumn{2}{|c|}{2825} \\
\hline
\end{tabular}


Um argumento para essa diferença pode ser encontrado em Pereira e Ruiz (2006). Os autores destacam que mesmo dentro das RM brasileiras há fortes diferenças de infra-estrutura. Afirmam que os municípios com elevada capacidade de se "apropriarde-rendas" são dotados de ótima infra-estrutura domiciliar (e.g. saneamento, iluminação, água encanada), enquanto os municípios com elevada "geração-de-produto" possuem limitada infra-estrutura domiciliar, onde também estão localizadas parcelas da população com baixa renda domiciliar. Essa organização espacial dual e articulada está captada nos modelos econométricos com sinais e significância diferenciadas na variável saneamento quando explicam Renda e PIB.

\subsection{Determinantes das Aglomeraçôes Econômicas Espaciais no Nordeste}

A Tabela 5 apresenta o resultado de dois modelos para a região Nordeste. Para essa região, as características da base industrial são também altamente correlacionadas. Assim, a configuração usual da indústria pelas características da demanda está no primeiro modelo (intermediários, capital e duráveis, de consumo e extrativos), enquanto uma divisão da indústria por critérios de inovação e preço-prêmio está no segundo modelo (firmas inovadoras, padronizadas e competitivas).

No primeiro modelo, os únicos coeficientes negativos significativos são o custo de transporte para a capital, o que indica que a renda é maior em espaços próximos às capitais estaduais. A variável Custo de Transporte - SP não foi significativa em nenhum modelo, o que mostra a relevância das capitais estaduais nordestinas como ordenadoras da produção regional, não obstante a força da aglomeração paulista. No primeiro modelo os serviços não são significativos e no segundo modelo são os depósitos a prazo os não significativos. ${ }^{8}$

A presença da indústria de bens intermediários e de firmas inovadoras é determinante de uma renda municipal mais elevada. Assim, para o Nordeste, a indústria de bens intermediários e as firmas inovadoras mostram-se como um dos propulsores da polarização econômica. Já nos casos da indústria extrativa e de firmas competitivas, estas também possuem capacidade de geração de riqueza, mas numa escala inferior. O mesmo vale para a maior proximidade da capital estadual: o entorno da capital é a área preferencial de localização das atividades produtivas. Outros fatores que apresentaram elevado impacto na renda e no produto foram melhor qualificação da força de trabalho e maior produção tecnológica, contudo, de forma mais tênue quando comparado com o Sul-Sudeste.

8 Os modelos mostraram um bom ajuste, medido tanto pelo $R^{2}$ elevado como pelos mapas dos resíduos. Por exemplo, no segundo modelo da Tabela 4 apenas 89 municípios apresentaram erro acima de $+/-2$ desvios padrão. 
O resultado dos dois modelos para o PIB municipal é apresentado na Tabela 6 e segue o mesmo padrão do utilizado nos modelos para Renda. A única variável não significativa a $5 \%$ nos dois modelos é, novamente, o saneamento. Os sinais dos coeficientes são os esperados (positivos) para educação superior, patentes, PIB agropecuária, depósitos a prazo e serviços. O único coeficiente negativo foi para o custo de transporte para a capital e indica que o PIB é maior em espaços próximos às capitais estaduais. A variável Custo de Transporte - SP não foi significativa em nenhum dos dois modelos, e no primeiro modelo os serviços não são significativos a $5 \%$.

Os coeficientes da base industrial indicam uma hierarquia da composição industrial um pouco diferente em relação à hierarquia de renda. No caso do PIB, a presença da indústria de bens de capital e duráveis e de firmas inovadoras é seu principal determinante; já na renda a liderança coube à indústria de intermediários combinada com a presença de firmas inovadoras. A indústria extrativa e as firmas competitivas mantiveram-se como as estruturas produtivas com menor capacidade de geração de renda.

Não há dúvidas sobre a relevância das empresas inovadoras nos dois casos analisados (Sul-Sudeste e Nordeste), mas há uma polêmica sobre em quais setores essas empresas deveriam estar: no setor de bens intermediários ou de bens de capital e duráveis. Na região Sul-Sudeste a presença mais marcante é do setor produtor de bens de capital e duráveis, o que pode ser um indicador da direção a ser seguida pelos Estados do Nordeste, uma vez que no Sul-Sudeste estão localizadas as maiores concentrações econômicas do Brasil e aquelas com maior nível de renda per capita. 
TABELA 5 - MODELOS PARA A RENDA - NORDESTE

\begin{tabular}{|c|c|c|c|c|}
\hline \multicolumn{5}{|c|}{ Variável Dependente: RENDA } \\
\hline \multirow[b]{2}{*}{ Variável Independente } & \multicolumn{2}{|c|}{ Modelo 1} & \multicolumn{2}{|c|}{ Modelo 2} \\
\hline & Coeficiente & z-value & Coeficiente & z-value \\
\hline Variável Dependente defasada Renda & 0.137 & 5.588 & 0.141 & 5.828 \\
\hline Constante & 0.212 & 1.011 & 0.138 & 0.664 \\
\hline Saneamento & 0.016 & 2.274 & 0.018 & 2.502 \\
\hline Área & 0.178 & 12.754 & 0.172 & 12.460 \\
\hline Educação Superior & 0.118 & 7.114 & 0.119 & 7.146 \\
\hline Custo de Transporte - SP & -0.027 & -0.941 & -0.018 & -0.630 \\
\hline Custo de Transporte - Capital & -0.593 & -12.028 & -0.584 & -11.900 \\
\hline Patentes & 0.012 & 2.034 & 0.040 & 3.406 \\
\hline Depósitos a Prazo & 0.040 & 3.204 & 0.006 & 1.197 \\
\hline PIB Agropecuária & 0.032 & 6.236 & 0.039 & 7.090 \\
\hline Serviços & 0.015 & 1.647 & 0.529 & 12.520 \\
\hline Bens Intermediários & 0.507 & 11.665 & & \\
\hline Bens de Capital e Duráveis & 0.221 & 15.709 & & \\
\hline Bens de Consumo & 0.128 & 22.455 & & \\
\hline Indústria Extrativa & 0.024 & 7.530 & & \\
\hline Firmas Inovadoras & & & 0.227 & 16.636 \\
\hline Firmas Padronizadas & & & 0.127 & 22.358 \\
\hline Firmas Competitivas & & & 0.026 & 8.109 \\
\hline $\mathrm{R}^{2}$ & \multicolumn{2}{|c|}{0.825} & \multicolumn{2}{|c|}{0.826} \\
\hline Modelo & \multicolumn{2}{|c|}{ Defasagem } & \multicolumn{2}{|c|}{ Defasagem } \\
\hline $\mathrm{N}^{\circ}$ de Observações & \multicolumn{2}{|c|}{1787} & \multicolumn{2}{|c|}{1787} \\
\hline
\end{tabular}


TABELA 6- MODELOS PARA O PIB - NORDESTE

\begin{tabular}{|c|c|c|c|c|}
\hline \multicolumn{5}{|c|}{ Variável Dependente: PIB } \\
\hline \multirow[b]{2}{*}{ Variável Independente } & \multicolumn{2}{|c|}{ Modelo 1} & \multicolumn{2}{|c|}{ Modelo 2} \\
\hline & Coeficiente & z-value & Coeficiente & z-value \\
\hline Variável Dependente defasada PIB & 0.209 & 8.298 & 0.219 & 9.141 \\
\hline Constante & 3.909 & 14.199 & 3.720 & 13.703 \\
\hline Saneamento & -0.006 & -0.862 & -0.005 & -0.838 \\
\hline Área & 0.131 & 10.043 & 0.134 & 10.164 \\
\hline Educação Superior & 0.130 & 8.845 & 0.135 & 9.371 \\
\hline Custo de Transporte - SP & -0.013 & -0.569 & -0.001 & -0.039 \\
\hline Custo de Transporte - Capital & -0.620 & -14.430 & -0.591 & -13.933 \\
\hline Patentes & 0.052 & 7.631 & 0.067 & 5.210 \\
\hline Depósitos a Prazo & 0.075 & 4.838 & 0.050 & 8.876 \\
\hline PIB Agropecuária & 0.033 & 5.816 & 0.051 & 10.739 \\
\hline Serviços & 0.023 & 1.820 & 0.286 & 7.021 \\
\hline Bens Intermediários & 0.236 & 5.072 & - & - \\
\hline Bens de Capital e Duráveis & 0.275 & 17.663 & - & - \\
\hline Bens de Consumo & 0.086 & 16.258 & - & - \\
\hline Indústria Extrativa & 0.024 & 7.472 & - & - \\
\hline Firmas Inovadoras & - & - & 0.272 & 17.922 \\
\hline Firmas Padronizadas & - & - & 0.084 & 16.193 \\
\hline Firmas Competitivas & - & - & 0.022 & 6.897 \\
\hline $\mathrm{R}^{2}$ & \multicolumn{2}{|c|}{0.859} & \multicolumn{2}{|c|}{0.860} \\
\hline Modelo & \multicolumn{2}{|c|}{ Defasagem } & \multicolumn{2}{|c|}{ Defasagem } \\
\hline № de Observações & \multicolumn{2}{|c|}{1787} & \multicolumn{2}{|c|}{1787} \\
\hline
\end{tabular}

\section{DIFERENCIAÇÃO ENTRE AS ESTRUTURAS DAS AGLOMERAÇÕES ESPACIAIS}

Os modelos econométricos apresentados avaliam a interação entre as várias firmas e estruturas municipais em uma determinada região; contudo, esses modelos pouco informam sobre as características específicas das aglomerações que surgem nessas áreas. Assim, nas duas regiões estudadas foram criadas as aglomeraçôes econômicas espaciais (AEEs), que seriam aqueles municípios com elevada correlação espacial de renda e PIB (locais com elevada renda e PIB com alta correlação positiva com seus vizinhos - high-high).

Existem diferenças importantes entre as AEEs identificadas nas Figuras 2 e 3 e relações caracterizadas pelos modelos econométricos. A AEE paulista, que se estende 
no eixo São Paulo-Campinas é a que apresenta a maior escala: possui cerca de 33\% da renda e do PIB de toda a região (Sul-Sudeste). Em seguida temos a AEE carioca, com 15\% da renda, na seqüência temos as AEEs de Porto Alegre, Belo Horizonte e Curitiba, todas com uma escala próxima a 4,5\%; a AEE de Vitória encontra-se em outra escala, com apenas $2 \%$ da renda (Tabela 7 ).

Essas AEEs possuem estruturas diferenciadas. Observando as AEEs pela sua capacidade inovadora, a de São Paulo possui 50\% das empresas inovadoras, em seguida temos Curitiba, com 7\% e Rio, Belo Horizonte e Porto Alegre com 4,3\% cada uma. Surpreende nesses dados a fragilidade da AEE carioca, pois sua capacidade inovadora está muito abaixo da sua escala absoluta. Essa fragilidade é confirmada pela sua estrutura interna: há um forte predomínio de empresas padronizadas e concentradas nos setores intermediários, certamente um resultado da elevada participação da indústria petroquímica. Na AEE carioca, a grande pujança está nos serviços, que correspondem a $20 \%$ do total da região Sul-Sudeste. A fragilidade industrial carioca só é superada pela da AEE de Vitória, onde o peso da indústria de intermediários com firmas padronizadas é mais intenso: 93\% da atividade industrial (Tabela 7).

\section{TABELA 7 - AGLOMERAÇÕES ECONÔMICAS ESPACIAIS DO SUL E DO SUDESTE ${ }^{l}$}

\begin{tabular}{lrrrrrrr}
\hline $\begin{array}{l}\text { Aglomerações } \\
\text { Econômicas Espaciais }\end{array}$ & $\begin{array}{c}\text { São } \\
\text { Paulo }\end{array}$ & $\begin{array}{c}\text { Rio de } \\
\text { Janeiro }\end{array}$ & $\begin{array}{c}\text { Belo } \\
\text { Horizonte }\end{array}$ & Vitória & $\begin{array}{c}\text { Curitiba- } \\
\text { Joinvile }\end{array}$ & $\begin{array}{c}\text { Porto } \\
\text { Alegre- } \\
\text { Caxias }\end{array}$ & Total \\
\hline Número de Municípios & 129 & 56 & 34 & 14 & 45 & 31 & 309 \\
PIB & 32,9 & 13,2 & 4,6 & 1,8 & 4,0 & 4,7 & 61,2 \\
Renda & 32,7 & 14,7 & 4,8 & 1,5 & 4,3 & 4,9 & 62,9 \\
Depósitos a Prazo & 59,8 & 12,3 & 4,8 & 1,4 & 5,6 & 5,6 & 89,4 \\
Patentes & 45,9 & 8,9 & 6,5 & 1,2 & 7,1 & 6,6 & 76,2 \\
População & 25,4 & 12,8 & 4,6 & 1,6 & 3,7 & 3,9 & 52,1 \\
\hline Firmas Inovadoras & 47,8 & 4,2 & 4,3 & 0,2 & 6,9 & 4,3 & 67,7 \\
Firmas Padronizadas & 35,8 & 8,4 & 4,3 & 2,9 & 5,6 & 6,6 & 63,6 \\
Firmas Competitivas & 32,8 & 7,8 & 6,7 & 1,1 & 4,2 & 5,7 & 58,4 \\
\hline Bens Intermediários & 44,3 & 10,6 & 4,2 & 2,7 & 4,9 & 6,9 & 73,5 \\
Bens de Capital e & 45,7 & 2,5 & 6,4 & 0,2 & 10,3 & 5,6 & 70,7 \\
Duráveis & 27,6 & 5,3 & 2,4 & 0,9 & 4,7 & 5,2 & 46,0 \\
Bens de Consumo & 2,2 & 0,7 & 9,0 & 4,8 & 0,2 & 0,1 & 17,0 \\
Ind. Extrativa & 3,4 & 1,1 & 0,4 & 0,4 & 1,4 & 1,1 & 7,8 \\
\hline PIB Agropecuário & 48,9 & 20,3 & 5,8 & 1,2 & 4,5 & 4,4 & 85,2 \\
Serviços & & & & & & & \\
\hline
\end{tabular}

Nota: (1) \% do total do Sul e do Sudeste (2.825 municípios)

Fonte: Elaboração própria a partir da Base Industrial Municipal (IPEA/CEDEPLAR). 


\section{TABELA 8 - AGLOMERAÇÕES ECONÔMICAS ESPACIAIS DO SUL E DO SUDESTE}

\begin{tabular}{lrrrrrr}
\hline $\begin{array}{l}\text { Aglomerações Econômicas } \\
\text { Espaciais }\end{array}$ & São Paulo & $\begin{array}{c}\text { Rio de } \\
\text { Janeiro }\end{array}$ & $\begin{array}{c}\text { Belo } \\
\text { Horizonte }\end{array}$ & Vitória & $\begin{array}{c}\text { Curitiba- } \\
\text { Joinvile }\end{array}$ & $\begin{array}{c}\text { Porto Alegre- } \\
\text { Caxias }\end{array}$ \\
\hline Bens Intermediários & 57,9 & 75,7 & 47,3 & 75,2 & 42,7 & 59,3 \\
Bens de Capital e Duráveis & 26,7 & 8,1 & 32,4 & 2,6 & 40,0 & 21,6 \\
Bens de Consumo & 15,1 & 15,7 & 11,2 & 10,4 & 17,1 & 19,1 \\
Ind. Extrativa & 0,3 & 0,5 & 9,1 & 11,8 & 0,2 & 0,05 \\
\hline Total da Indústria & 100,0 & 100,0 & 100,0 & 100,0 & 100,0 & 100,0 \\
\hline Firmas Inovadoras & 34,7 & 16,5 & 27,1 & 2,9 & 33,4 & 20,9 \\
Firmas Padronizadas & 59,4 & 75,9 & 62,4 & 93,2 & 61,6 & 72,4 \\
Firmas Competitivas & 5,9 & 7,6 & 10,5 & 3,9 & 5,1 & 6,8 \\
\hline Total das Firmas & 100,0 & 100,0 & 100,0 & 100,0 & 100,0 & 100,0 \\
\hline
\end{tabular}

Nota: (1) \% do total do Sul e do Sudeste (2.825 municípios)

Fonte: Elaboração própria a partir da Base Industrial Municipal (IPEA/CEDEPLAR).

As AEEs mineira, gaúcha e paranaense-catarinense apresentam estruturas mais inovadoras e diversificadas que a carioca e capixaba. Nessas três AEEs as firmas inovadoras respondem por mais de $20 \%$ do produto industrial, que se encontra relativamente disperso na indústria de bens de capital e bens intermediários (Tabela 9). A AEE de Curitiba-Joinville é a que mostra uma pequena vantagem relativa, pois as firmas inovadoras correspondem a $33 \%$ do produto - valor equivalente ao verificado para a paulista - e o peso do setor de bens de capital e de duráveis supera significativamente os valores registrados para as AEEs mineira e gaúcha. Dentre essas três AEEs de terceira ordem, a gaúcha é a mais fragilizada em termos de capacidade inovadora e a mais especializada em produtos intermediários.

Dadas essas diferenças internas e de escala, pode-se afirmar que as AEEs de Belo Horizonte e de Curitiba-Joinville são as concorrentes mais próximas da AEE primaz paulista e da enfraquecida AEE carioca; uma conclusão que vai ao encontro de outras análises que identificaram desvantagens relativas da concentração industrial da AEE mineira em relação à paranaense (LEMOS; CROCCO, 2000). Nesse estudo, a AEE de Belo Horizonte é da escala da AEE de Curitiba-Joinville. Essa equivalência, entretanto, é compensada favoravelmente pela estrutura interna da AEE paranaense: sua composição mostra significativa concentração em setores produtores de duráveis e bens de capital e de empresas inovadoras.

A AEE mineira, por sua vez, apresenta um predomínio mais acentuado de indústrias intermediárias, extrativas, padronizadas e competitivas, todas indicando uma baixa densidade tecnológica, em que pese a importância crescente do setor de material de transportes. A limitada diversificação produtiva da AEE de Belo Horizonte torna 
problemático o estabelecimento de uma ancoragem espacial para ampliação dos ativos industriais que vão além das vantagens locacionais "weberianas".

Outro ponto de destaque é que a AEE Curitiba-Joinville mostra-se capaz de se estender por amplas áreas no interior dos Estados, o que tende a minimizar custos decorrentes da aglomeração excessiva. A AEE mineira é intensamente polarizada pela RM de Belo Horizonte, de fato a AEE e a RM são quase similares no que tange à sua dimensão geográfica. Essa concentração da AEE na RM de Belo Horizonte pode ser uma indicação da ainda limitada capacidade do Estado de ampliar para os municípios do entorno as condições tecno-produtivas e de infra-estrutura demandadas pela produção industrial.

Para finalizar, vale notar que dentro da AEE paulista a cidade de Campinas é outro concorrente locacional que apresenta escala industrial e significativa capacidade inovativa. Campinas é uma extensão da AEE metropolitana paulista e tem fortes complementaridades com a indústria paulistana, além de uma proximidade com aglomerações médias de São José dos Campos, Sorocaba e de Ribeirão Preto.

As Tabelas 9 e 10 descrevem as estruturas produtivas das maiores aglomerações econômicas do Nordeste. Como esperado, Salvador, Recife e Fortaleza são as grandes AEEs, sendo a baiana a aglomeração de primeira ordem, enquanto as outras duas aglomeraçóes podem ser consideradas de segunda ordem. Dentre as aglomerações de terceira ordem está Juazeiro-Petrolina, uma aglomeração com pequena escala e que tem apresentado elevadas taxas de crescimento. Arriscamos, portanto, classificála como uma aglomeração incipiente e alternativa às aglomerações metropolitanas da Bahia e de Pernambuco - certamente uma novidade no que tange à ordenação espacial do interior nordestino.

A participação de firmas padronizadas e competitivas nas AEEs nordestinas é significativamente superior à verificada para as AEEs do Sul-Sudeste; o caso extremo é Juazeiro-Petrolina, onde o peso das firmas competitivas se aproxima dos $50 \% \mathrm{com}$ quase $100 \%$ das suas indústrias no setor de bens de consumo. Outro ponto que merece destaque para o conjunto das AEEs nordestinas é a participação das AEEs no produto industrial da região: essas AEEs respondem por $89 \%$ do produto das firmas inovadoras e $80 \%$ do produto das firmas padronizadas; no Sul-Sudeste esses valores são $68 \%$ e $63 \%$, respectivamente. Portanto, no Nordeste há uma precária e limitada capacidade industrial localizada fora das AEEs com capacidade de se inserir competitivamente no mercado externo (firmas inovadoras e padronizadas).

Comparativamente, a AEE de Salvador é a que apresenta a maior escala, uma estrutura mais inovativa e com maior participação de bens intermediários. Na AEE 
baiana está concentrado $68 \%$ do produto das firmas inovadoras do Nordeste; já no Sul-Sudeste a AEE de São Paulo possui apenas 48\% das firmas inovadoras. Contudo, a AEE de Salvador responde por apenas 18\% do PIB e 12\% da renda da região, enquanto a AEE de São Paulo concentra 33\% da renda e do PIB da região Sul-Sudeste. Portanto, o Nordeste é mais descentralizado no que tange à renda, mas mais polarizado no que se refere à tecnologia. No Sul-Sudeste ocorre o inverso: a AEE de São Paulo é uma grande aglomeração, mas a região tem uma dispersa capacidade tecnológica. Um leitor com forte viés schumpteriano apostaria numa descentralização mais rápida na região Sul-Sudeste e em maiores dificuldades na descentralização no espaço nordestino.

Recife e Fortaleza são as duas AEEs que competem com a AEE baiana, mas possuem estruturas muito diferenciadas. Recife, a segunda maior AEE, apresenta baixa participação de firmas inovadoras, mas com peso significativo dos setores produtores de bens intermediários. A AEE de Fortaleza também apresenta baixa participação de firmas inovadoras, mas liderança setorial na produção de bens de consumo. Portanto, as bases científicas e tecnológicas dessas duas AEEs concorrentes da baiana não foram capazes de gerar uma estrutura industrial mais inovadora. O caso de Recife é o que apresenta o maior descompasso: possui mais de $22 \%$ das patentes, mas um pouco mais de $7 \%$ do seu produto industrial vem de firmas inovadoras.

De modo geral, nas AEEs nordestinas a participação dos setores de bens de consumo e de firmas não-inovadoras é elevada quando comparada com as AEEs do SulSudeste. Nas AEEs nordestinas de terceira ordem o setor de bens de consumo corresponde, em geral, a mais de $40 \%$ do produto; as exceções seriam São Luís e Aracaju, com peso elevado das atividades intermediárias e extrativistas, respectivamente. No Sul-Sudeste não se verifica um peso elevado dos setores de consumo e extrativista e um baixo peso de firmas inovadoras, em particular nas AEEs de segunda ordem, como Belo Horizonte, Curitiba-Joinville e Porto Alegre-Caxias.

Na região Sul-Sudeste uma hipótese que explicaria essa menor participação dos bens de consumo e do maior peso das firmas inovadoras estaria no fato de na região já existirem localidades capazes de sediar atividades industriais fora das AEEs, pelo menos aquelas com menor complexidade tecnológica (firmas competitivas e nãoinovadoras). No Nordeste tal capacidade ainda é limitada, o que restringe o leque de alternativas locacionais para as firmas industriais. Assim, os dados sugerem que os espaços não-metropolitanos no Nordeste possuem poucos atrativos para a localização ou expansão da atividade industrial; não é por outra razão que a aglomeração de Juazeiro-Petrolina surpreende positivamente. Já no Sul-Sudeste as firmas competitivas e de bens de consumo se localizariam fora das AEEs, locais menos custosos para 
suas atividades produtivas, o que reduziria sua presença nas grandes aglomerações econômicas.

TABELA 9A - AGLOMERAÇÕES ECONÔMICAS ESPACIAIS DO NORDESTE ${ }^{I}$

\begin{tabular}{lrrrrr}
\hline $\begin{array}{l}\text { Aglomerações Econômicas } \\
\text { Espaciais }\end{array}$ & Salvador & Recife & Fortaleza & Natal & São Luís \\
\hline Número de Municípios & 30 & 22 & 26 & 12 & 27 \\
PIB & 18,2 & 12,5 & 9,5 & 3,3 & 3,0 \\
Renda & 12,9 & 13,0 & 10,6 & 4,2 & 3,6 \\
Depósitos a Prazo & 26,8 & 19,5 & 22,7 & 2,9 & 6,0 \\
Patentes & 16,8 & 22,4 & 17.2 & 6,7 & 4,7 \\
População & 7,1 & 7,5 & 6,9 & 2,4 & 3,0 \\
\hline Firmas Inovadoras & 68,3 & 7,3 & 8,6 & 0,5 & 1,0 \\
Firmas Padronizadas & 37,6 & 10,2 & 12,0 & 6,6 & 3,2 \\
Firmas Competitivas & 11,2 & 14,6 & 11,3 & 2,6 & 2,5 \\
\hline Bens Intermediários & 5,6 & 5,2 & 3,9 & 2,1 & 1,8 \\
Bens de Capital e Duráveis & 12,6 & 13,6 & 12,4 & 0,4 & 0,0 \\
Bens de Consumo & 1,7 & 5,1 & 6,4 & 1,8 & 0,5 \\
Ind. Extrativa & 3,9 & 0,1 & 3,1 & 4,7 & 6,0 \\
PIB Agropecuário & 2,1 & 2,4 & 1,8 & 0,5 & 0,9 \\
Serviços & 25,5 & 23,7 & 14,2 & 4,6 & 3,9 \\
\hline
\end{tabular}




\section{TABELA 9B - AGLOMERAÇÕES ECONÔMICAS ESPACIAIS DO NORDESTE ${ }^{1}$}

\begin{tabular}{lccccc}
\hline Aglomerações Econômicas Espaciais & Maceió & Aracaju & $\begin{array}{r}\text { João } \\
\text { Pessoa }\end{array}$ & $\begin{array}{r}\text { Petrolina } \\
\text { Juazeiro }\end{array}$ & Total \\
\hline Número de Municípios & 14 & 16 & 9 & 15 & 171 \\
PIB & 2,8 & 2,8 & 2,5 & 1,6 & 56,2 \\
Renda & 3,5 & 2,8 & 3,3 & 1,5 & 55,2 \\
Depósitos a Prazo & 3,1 & 4,9 & 1,5 & 0,4 & 87,9 \\
Patentes & 3,7 & 2,8 & 5,7 & 3,4 & 83,2 \\
População & 2,3 & 1,8 & 1,9 & 1,6 & 34,5 \\
\hline Firmas Inovadoras & 1,0 & 0,1 & 2,5 & 0,0 & 88,9 \\
Firmas Padronizadas & 4,9 & 4,5 & 2,1 & 0,3 & 81,3 \\
Firmas Competitivas & 5,3 & 5,4 & 4,1 & 2,0 & 59,0 \\
\hline Bens Intermediários & 1,8 & 2,0 & 1,0 & 0,4 & 23,9 \\
Bens de Capital e Duráveis & 0,3 & 7,5 & 0,2 & 3,4 & 50,4 \\
Bens de Consumo & 2,9 & 1,7 & 2,5 & 1,3 & 23,9 \\
Ind. Extrativa & 0,2 & 7,0 & 0,0 & 0,0 & 25,0 \\
\hline PIB Agropecuário & 0,7 & 0,7 & 0,9 & 4,3 & 14,2 \\
Serviços & 3,3 & 3,8 & 3,8 & 1,0 & 83,7 \\
\hline
\end{tabular}

Nota: (1) \% do total do Nordeste (1.787 municípios).

Fonte: Elaboração própria a partir da Base Industrial Municipal (IPEA/CEDEPLAR).

\section{TABELA IOA - AGLOMERAÇÕES ECONOAMICAS ESPACIAIS DO NORDESTE ${ }^{1}$}

\begin{tabular}{lcrrrr}
\hline Aglomerações Econômicas Espaciais & Salvador & Recife & Fortaleza & Natal & São Luís \\
\hline Bens Intermediários & 81,5 & 54,9 & 24,9 & 3,6 & 85,8 \\
Bens de Capital e Duráveis & 7,1 & 11,5 & 5,3 & 0,6 & 0,7 \\
Bens de Consumo & 4,7 & 33,4 & 69,4 & 35,1 & 12,9 \\
Ind. Extrativa & 6,7 & 0,2 & 0,4 & 60,7 & 0,6 \\
\hline Total da Indústria & 100,0 & 100 & 100 & 100 & 100 \\
\hline Firmas Inovadoras & 13,7 & 5,0 & 5,5 & 0,6 & 2,4 \\
Firmas Padronizadas & 83,1 & 80,0 & 84,1 & 94,6 & 88,7 \\
Firmas Competitivas & 3,2 & 15,0 & 10,4 & 4,8 & 8,9 \\
\hline Total das Firmas & 100,0 & 100 & 100,0 & 100,0 & 100,0 \\
\hline
\end{tabular}




\section{TABELA IOB - AGLOMERAÇÕES ECONÔMICAS ESPACIAIS DO NORDESTE ${ }^{1}$}

\begin{tabular}{lrrrrr}
\hline Aglomerações Econômicas Espaciais & Maceió & Aracaju & João Pessoa & $\begin{array}{c}\text { Petrolina } \\
\text { Juazeiro }\end{array}$ & Total \\
\hline Bens Intermediários & 53,4 & 28,6 & 24,9 & 3,2 & 57,9 \\
Bens de Capital e Duráveis & 1,5 & 3,4 & 1,5 & 0,1 & 6,0 \\
Bens de Consumo & 44,5 & 25,0 & 73,5 & 96,6 & 26,2 \\
Ind. Extrativa & 0,6 & 43,0 & 0,1 & 0,1 & 9,9 \\
\hline Total da Indústria & 100,0 & 100,0 & 100,0 & 100,0 & 100,0 \\
\hline Firmas Inovadoras & 1,5 & 0,2 & 7,9 & 0,0 & 8,3 \\
Firmas Padronizadas & 86,2 & 86,2 & 73,2 & 53,0 & 83,7 \\
Firmas Competitivas & 12,3 & 13,6 & 18,9 & 47,0 & 8,0 \\
\hline Total das Firmas & 100,0 & 100,0 & 100,0 & 100,0 & 100,0 \\
\hline
\end{tabular}

Nota: (1) \% do total do Nordeste (1.787 municípios).

Fonte: Elaboração própria a partir da Base Industrial Municipal (IPEA/CEDEPLAR).

Do ponto de vista da organização industrial espacial, espera-se teoricamente que as firmas inovadoras e padronizadas sejam as "firmas centrais" e as firmas competitivas sejam as "firmas periféricas", ou seja, aquelas fora das AEEs. Essas "firmas centrais" tenderiam a possuir maiores exigências locacionais, demandar mão-de-obra mais qualificada e uma diversidade maior de serviços e amenidades urbanas. Os mercados nacional e internacional seriam seus mercados-alvo. As empresas inovadoras e padronizadas tenderiam a se localizar em grandes centros industriais, demandar complexa infra-estrutura produtiva e urbana, arcar com seus correspondentes altos custos e ter elevada escala e escopo de produção.

No outro lado dessa hierarquia estariam as "firmas periféricas", que tenderiam a ofertar para mercados regionais ou mesmo locais. Seus requisitos quanto à infraestrutura urbana, à qualificação da mão-de-obra e à atividades complementares seriam mínimos. Essas firmas teriam limitada capacidade de arcar com elevados custos urbanos, dada a concorrência em preços e a baixa capacidade de diferenciação tecnológica, o que as dispersaria pelo entorno e fora das AEEs.

Essa descrição hiperestilizada das preferências locacionais de "firmas centrais" e de "firmas periféricas" parece estar mais em sintonia com as AEEs do Sul-Sudeste. Já para o caso do Nordeste, as restrições à dispersão espacial parecem ser tão elevadas que o padrão industrial "centro-periferia" não se verifica: as firmas inovadoras convivem com firmas competitivas e todas elas estão concentradas nas áreas metropolitanas. É certo que tal especulação sobre a organização espacial e industrial das duas regióes estudadas deve ser ponderada pela composição das suas estruturas industriais. 
Entretanto, acreditamos que, em alguma magnitude, a ausência de uma organização espacial "centro-periferia" no Nordeste reflita as imensas restrições decorrentes da limitada capacidade de áreas não-metropolitanas de sediar atividades industriais, tal como já ocorre no interior de vários Estados da região Sul-Sudeste.

\section{CONSIDERAÇÕES FINAIS: OBSTÁCULOS À INCORPORAÇÃO PRO- GRESSIVA DAS PERIFERIAS}

Dadas as características das aglomerações econômicas analisadas neste trabalho, pode-se especular sobre os limites de um desenvolvimento regional "progressivo" ou por "fases". ${ }^{9}$ Nos termos dessa pesquisa, a hipótese da progressividade argumentaria que a industrialização na periferia seria liderada por firmas não-inovadoras e competitivas - predominantemente de capital nacional - que optariam por se localizar em espaços com menor custo e nas proximidades dos centros de concentração da renda. Num momento subseqüente, esse movimento seria acompanhado pela co-localização de firmas inovadoras e/ou diferenciadas. Portanto, tentativas de industrialização focadas nas firmas inovadoras seriam custosas, pois demandariam a criação de dispendiosas bases científicas e tecnológicas, de mercados com mão-de-obra qualificada e de uma complexa rede de serviços, de transporte e de comunicação. Em suma, uma industrialização puxada por firmas competitivas seria mais compatível com os limites materiais da região e, portanto, mais factível.

Não descartando a prudência implícita nessas políticas regionais, deve-se registrar que nesse estudo o sucesso de uma AEE está intimamente relacionado à presença marcante e em escala de empresas inovadoras. Para se sustentar, uma AEE deve ser capaz de acumular capacitações tecnológicas genéricas e de constituir uma variada infra-estrutura urbana. Pergunta-se: uma AEE suportada por firmas não-inovadoras e competitivas seria capaz de gerar excedentes suficientes para constituir tais capacitações e infra-estrutura de forma endógena e autônoma? Essas aglomerações dominadas por firmas competitivas possuiriam recursos capazes de ir além da depreciação corrente da sua estrutura regional e financiar com recursos próprios um "salto locacional” capaz de colocá-las como opção para as firmas inovadoras? Valeriam as propostas de "industrialização progressiva" na periferia ou se demandaria uma "ruptura" na estrutura regional de modo a impulsionar a região a um novo estágio?

9 Fujita et al. (1999, caps. 11 e 15) discutem uma industrialização na periferia que corresponde, em alguma medida, à industrialização "progressiva" aqui comentada. Vale notar, contudo, que mesmo nesse trabalho há ressalvas: os autores destacam em alguns casos poder ocorrer descontinuidade no processo de desenolvimento regional devido às descontinuidades tecnológicas combinadas com escalas de mercado potencial das diversas localidades. 
Por exemplo, no caso brasileiro, estaria a aglomeração econômica de JuazeiroPetrolina (BA-PE) em um momento crítico em que se requer uma "ruptura para cima” na sua estrutura econômica? Ou seja, estaria essa aglomeração nordestina no limite de suas capacidades internas de expansão, o que demandaria investimentos massivos - um big-push à Rosenstein-Rodan (1943) - para lançá-la a um estágio mais avançado de aglomeração econômica (escala, composição setorial, densidade tecnológica e inserção externa)? Também estariam em momentos críticos próprios outras economias regionais brasileiras, tais como as capitaneadas pelos municípios de Belém (PA), São Luiz (MA), Palmas (TO), Uberlândia (MG), Campo Grande (MS), Cuiabá (MT), Porto Velho (RO), Santarém (PA), Montes Claros (MG), Vitória da Conquista (BA), Crajaúba (Crato, Juazeiro do Norte e Barbalha - CE)?

Essas dúvidas quanto à "industrialização progressiva" surgem dos requisitos locais à instalação de empresas inovadoras, intensivas em escala e exportadoras que, de acordo com esse estudo, estão muito acima daqueles demandados por empresas não-inovadoras e competitivas. Em muitos casos não há contigüidade espacial entre os espaços ocupados por uma firma inovadora e outra não-inovadora. A desconcentração não se mostra, portanto, um evento de fácil implementação, ou seja, um movimento contínuo, progressivo e sem "saltos".

Nesse estudo identificamos uma relativa contigüidade na denominada região SulSudeste; contudo, na região Nordeste a fragmentação do espaço ainda mostra inúmeros bloqueios à dispersão espacial das atividades industriais. Em suma, no que tange a esse tema, avaliamos que é pouco provável ou muito difícil que esses espaços econômicos periféricos possam acumular endogenamente recursos capazes de lançálos a um estágio superior de estrutura econômica e, por certo, de renda e bem-estar social.

Essa é uma conclusão importante, pois hoje, em vários fóruns sobre políticas de desenvolvimento local, existem apostas - e consensos - entre agentes públicos (e.g. bancos, ministérios, agências de desenvolvimento local e secretarias estaduais) que os levam a focar suas políticas na reorganização interna das regiões. A aposta é que essas localidades seriam capazes de se conectar de forma virtuosa aos centros econômicos nacionais dominantes; para tanto, seria necessário se rearticular internamente a partir de suas lideranças econômicas locais.

Entendemos, entretanto, que várias dessas regiões - que seriam adjetivadas como "deprimidas” nos EUA - não possuem recursos materiais, tecnológicos, organizacionais e financeiros que, se recombinados, forneceriam uma nova base exportadora regional de produtos e serviços. Em termos mais acadêmicos: os insumos disponíveis são especializados, a função de produção é tecnicamente rígida, o escopo produtivo 
é restrito e há uma baixa capacidade de diferenciação de produtos. Nesse cenário, para saltar a um estágio superior de estrutura produtiva seria necessário um big-push regional, seja ele público ou privado.

Essas dúvidas, polêmicas e possíveis dificuldades na atração de investimentos propulsores do crescimento regional oferecem novos argumentos em favor de propostas de coordenação de políticas industriais, tecnológicas e de desenvolvimento regional. A ausência de uma articulação dessas políticas reduziria, por certo, suas eficiências individuais e diminuiria as possibilidades de sucesso na construção de novas centralidades urbanas em um território tão heterogêneo e ainda polarizado como o brasileiro.

\section{REFERENCIAS}

ALBUQUERQUE, E. A. et al. A distribuição espacial da produção científica e tecnológica brasileira: uma descrição de estatísticas de produção local de patentes e artigos científicos. Revista Brasileira de Inovação, v. 1, n. 2, 2002.

ANSELIN, L. Local indicator of spatial association - LISA. Geographical Analysis, v.27, n.3, p.93-115, 1995.

. The Moran scatterplot as an ESDA tool to assess local instability in spatial association. In: FISCHER, M.; SCHOLTEN, H. J. et al (Ed.). Spatial analytical perspectives on GIS in environmental and socio-economic sciences. London: Taylor and Francis, 1996.

. Exploratory spatial data analysis in geocomputacional environment. In: LONGLEY, P. A. et al. (Eds.) Geocompution, a primer. New York: John Wiley, 1998.

. The Moran scatterplot as an Esda tool to assess local instability in spatial association. In: FISCHER, M.; SCHOLTEN, H.J.; UNWIN, D. Spatial Analytical Perspectives on Gis, ed. by London: Taylor Francis, p.111-125, 1999.

. Under the hood. issues in the specification and interpretation of spatial regression models. Agricultural Economics, 2001.

AZZONI, C.R. Induistria e reversão da polarização no Brasil. São Paulo: IPE-USP, 1986.

- Concentração regional e dispersão das rendas per capita estaduais: análise a partir das séries históricas estaduais de PIB, 1939-1995. Estudos Econômicos, v.27, n.3, p. 341-393, 1997.

BECKER, B. K. Geopolítica da Amazônia. Estudos Avançados, v.19, n.53. São Paulo: Edusp, 2005.

DE NEGRI, J. A.; SALERMO, M. Inovação, padrốes tecnológicos e desempenho das firmas industriais brasileiras. Rio de Janeiro: IPEA, 2005. 
DINIZ, C. C. Desenvolvimento poligonal no Brasil: nem desconcentração, nem contínua polarização. Revista Nova Economia, 3 (1), p. 35-64, 1993.

. Polygonized development in Brazil: neither decentralization nor continued polarization. International Journal of Urban and Regional Research 18, p. 293314, 1994.

; CROCCO, M. A. A reestruturação econômica e impacto regional: o novo mapa da indústria brasileira. Revista Nova Economia, 6(1): p. 77-104, 1996.

DOMINGUES, E.P.; RUIZ, R.M. Aglomeraçôes industriais e tecnológicas: origem do capital, inovação e tecnologia. Belo Horizonte: CEDEPLAR/UFMG, 2005 (mimeo).

FUJITA, M; KRUGMAN, P.; VENABLES, A. J. The Spatial Economy - Cities, Regions, and International Trade. Cambridge, Massachussets; London, England: The MIT Press, 1999.

FURTADO, C. Formação econômica do Brasil. São Paulo: Fundo de Cultura, 1959.

HIRSCHMAN, A. The strategy of economic development. New Haven: Yale University Press, 1958.

LEMOS, M. B.; CROCCO, M. A. Competitividade e dinâmica comparativa das regiões metropolitanas brasileiras. UFMG/CEDEPLAR, 2000. (Texto para Discussão, n.146).

LEMOS, M. B. et al. A organização territorial da indústria no Brasil. In: DE NEGRI, J. A.; SALERMO, M. (eds.). Inovação, padrões tecnológicos e desempenho das firmas industriais brasileiras. Rio de Janeiro: IPEA, 2005a.

- Empresas estrangeiras em espaços periféricos: o caso brasileiro. In: DE NEGRI, J. A.; SALERMO, M. (Eds.). Inovação, padrões tecnológicos e desempenho das firmas industriais brasileiras. Rio de Janeiro: IPEA, $2005 \mathrm{~b}$.

- Espaços preferenciais e aglomerações industriais. In: DE NEGRI, J. A.; SALERMO, M. (Eds.). Inovação, padrões tecnológicos e desempenho das firmas industriais brasileiras. Rio de Janeiro: IPEA, 2005c.

LEMOS, M.B.; DINIZ, C.C., GUERRA, L.P., MORO, S. A nova configuração regional brasileira e sua geografia econômica. Estudos Econômicos, v. 33, n. 4, p. 665-700, 2003.

MYRDAL, G. Economy theory and under-development regions. Cap. 3/4. London, 1957.

MONTE-MÓR, R. L. Urbanização e modernidade na Amazônia contemporânea. In: LIMONAD, E.; HAESBAERT, R.; MOREIRA, R. (Eds.), Brasil século XXI por uma nova regionalização? São Paulo: Max Limonad, 2004, p. 112-122.

NURSKE, Ragnar. Problems of capital formation in underdeveloped countries. New York: Oxford University Press, 1953.

PEREIRA, F.B.; RUIZ, R.M. As Periferias nos centros: um estudo das estruturas metropolitanas brasileiras. XII Seminário sobre a Economia Mineira Economia, 
História, Demografia e Políticas Públicas. Diamantina, MG - 29 de agosto a $1^{\circ}$ de setembro de 2006.

PRADO, C. Histórica econômica do Brasil. São Paulo: Brasiliense, 1959.

RAY, Debraj. Development economics. Princeton, New Jersey: Princeton Universty Press, 1998.

ROSENSTEIN-RODAN, P. Problems of industrialization of eastern and south eastern Europe. Economic Journal, june-sept. 1943. 


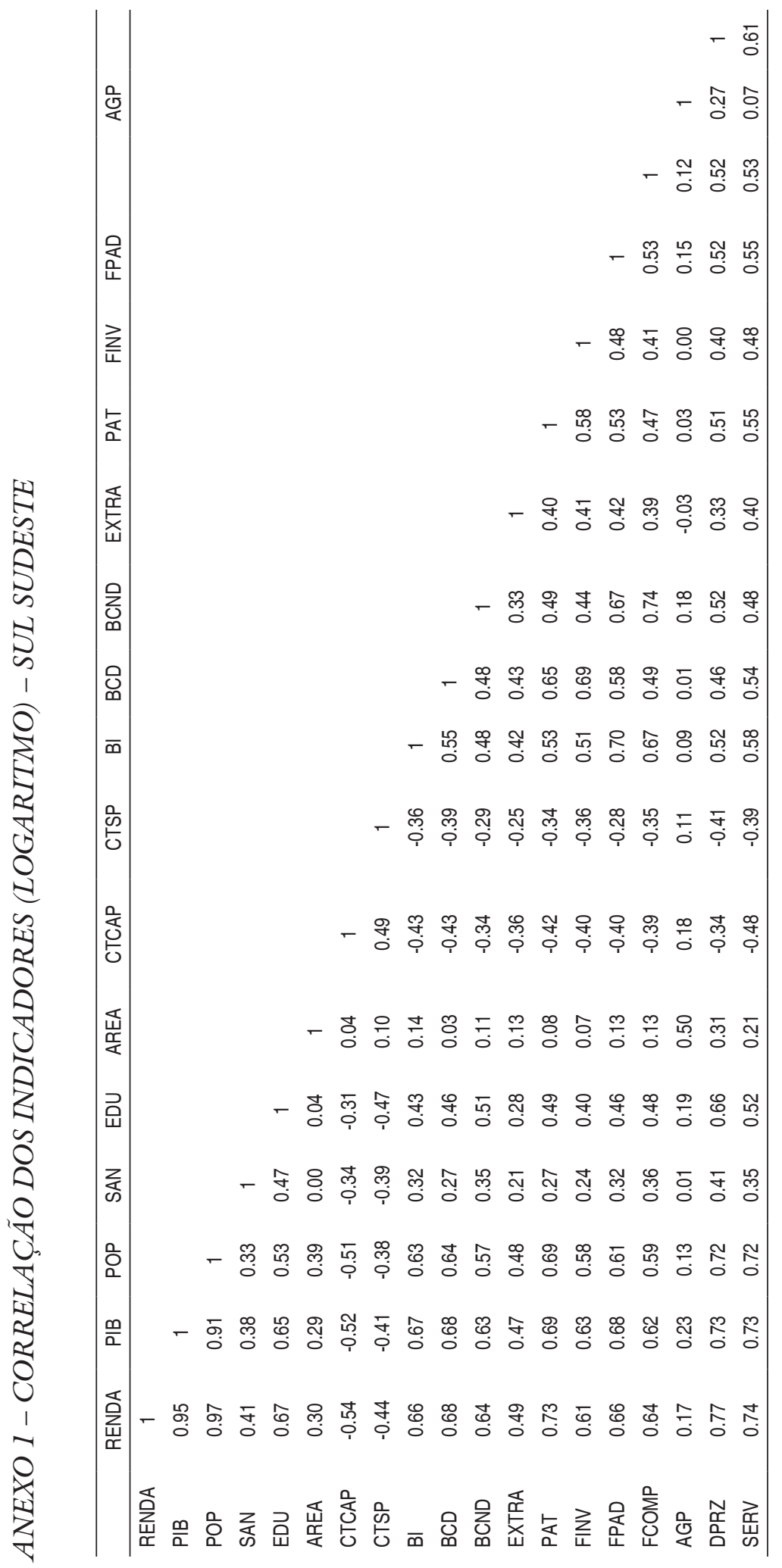




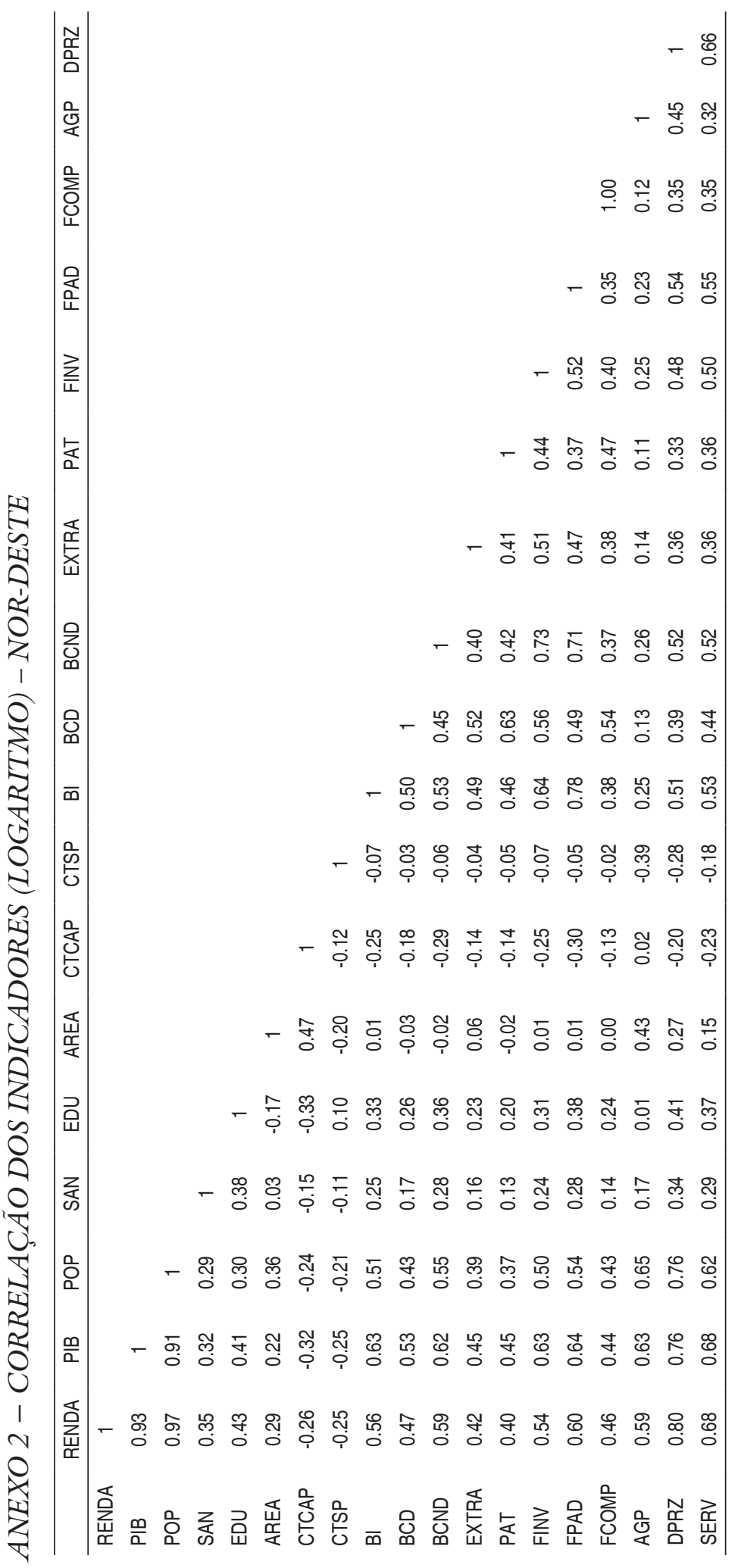

